\title{
Effect of dark sweet cherry powder consumption on the gut microbiota, short-chain fatty acids, and biomarkers of gut health in obese $\mathrm{db} / \mathrm{db}$ mice
}

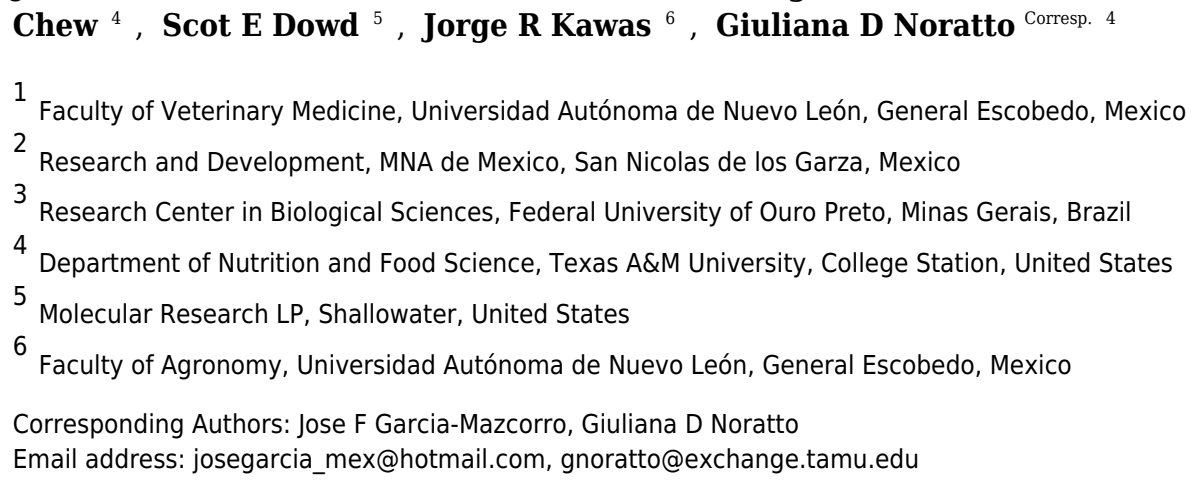

Cherries are fruits containing fiber and bioactive compounds (e.g. polyphenolics) with the potential of helping patients with diabetes and weight disorders, a phenomenon likely related to changes in the complex host-microbiota milieu. The objective of this study was to investigate the effect of cherry supplementation on the gut bacterial composition, concentrations of caecal short-chain fatty acids (SCFAs) and biomarkers of gut health using an in vivo model of obesity. Obese diabetic $(\mathrm{db} / \mathrm{db})$ mice received a supplemented diet with $10 \%$ cherry powder (supplemented mice, $n=12$ ) for 12 weeks; obese $(n=10)$ and lean $(n=10)$ mice served as controls and received a standard diet without cherry. Highthroughput sequencing of the 16S rRNA gene and quantitative real-time PCR (qPCR) were used to analyze the gut microbiota; SCFAs and biomarkers of gut health were also measured using standard techniques. According to $16 \mathrm{~S}$ sequencing, supplemented mice harbored a distinct colonic microbiota characterized by a higher abundance of mucindegraders (i.e. Akkermansia) and fiber-degraders (the S24-7 family) as well as lower abundances of Lactobacillus and Enterobacteriaceae. Overall this particular cherryassociated colonic microbiota did not resemble the microbiota in obese or lean controls based on the analysis of weighted and unweighted UniFrac distance metrics. qPCR confirmed some of the results observed in sequencing, thus supporting the notion that cherry supplementation can change the colonic microbiota. Moreover, the SCFAs detected in supplemented mice (caproate, methyl butyrate, propionate, acetate and valerate) exceeded those concentrations detected in obese and lean controls except for butyrate. Despite the changes in microbial composition and SCFAs, most of the assessed biomarkers 
of inflammation, oxidative stress, and intestinal health in colon tissues and mucosal cells were similar in all obese mice with and without supplementation. This paper shows that dietary supplementation with cherry powder for 12 weeks affects the microbiota and the concentrations of SCFAs in the lower intestinal tract of obese $\mathrm{db} / \mathrm{db}$ diabetic mice. These effects occurred in absence of differences in most biomarkers of inflammation and other parameters of gut health. Our study prompts more research into the potential clinical implications of cherry consumption as a dietary supplement in diabetic and obese human patients. 
1 Effect of dark sweet cherry powder consumption on the gut microbiota, short-chain fatty

2 acids, and biomarkers of gut health in obese $\mathrm{db} / \mathrm{db}$ mice

3 Jose F. Garcia-Mazcorro ${ }^{1,2}$, Nara Nunes Lage ${ }^{3,4}$, Susanne Mertens-Talcott ${ }^{4}$, Stephen Talcott ${ }^{4}$,

4 Boon Chew ${ }^{4}$, Scot E. Dowd ${ }^{5}$, Jorge R. Kawas ${ }^{6}$, and Giuliana D. Noratto ${ }^{4}$

5

$6{ }^{1}$ Faculty of Veterinary Medicine, Universidad Autonoma de Nuevo Leon (UANL), General

7 Escobedo, Nuevo Leon, Mexico

$8 \quad{ }^{2}$ MNA de Mexico, San Nicolas de los Garza, Nuevo Leon, Mexico

$9{ }^{3}$ Research Center in Biological Sciences, Federal University of Ouro Preto, Minas Gerais, Brazil

${ }^{4}$ Department of Nutrition and Food Science, Texas A\&M University, College Station, Texas,

11 USA

$12{ }^{5}$ Molecular Research LP, Shallowater, Texas, USA

$13{ }^{6}$ Faculty of Agronomy, UANL, General Escobedo, Nuevo Leon, Mexico

Corresponding: Giuliana Noratto, gnoratto@tamu.edu 
24 Abstract

25 Cherries are fruits containing fiber and bioactive compounds (e.g. polyphenolics) with the potential of helping patients with diabetes and weight disorders, a phenomenon likely related to changes in the complex host-microbiota milieu. The objective of this study was to investigate the effect of cherry supplementation on the gut bacterial composition, concentrations of caecal shortchain fatty acids (SCFAs) and biomarkers of gut health using an in vivo model of obesity. Obese diabetic $(\mathrm{db} / \mathrm{db})$ mice received a supplemented diet with $10 \%$ cherry powder (supplemented mice, $n=12)$ for 12 weeks; obese $(n=10)$ and lean $(n=10)$ mice served as controls and received a standard diet without cherry. High-throughput sequencing of the 16S rRNA gene and quantitative real-time PCR (qPCR) were used to analyze the gut microbiota; SCFAs and biomarkers of gut health were also measured using standard techniques. According to $16 \mathrm{~S}$ sequencing, supplemented mice harbored a distinct colonic microbiota characterized by a higher abundance of mucin-degraders (i.e. Akkermansia) and fiber-degraders (the S24-7 family) as well as lower abundances of Lactobacillus and Enterobacteriaceae. Overall this particular cherryassociated colonic microbiota did not resemble the microbiota in obese or lean controls based on the analysis of weighted and unweighted UniFrac distance metrics. qPCR confirmed some of the results observed in sequencing, thus supporting the notion that cherry supplementation can change the colonic microbiota. Moreover, the SCFAs detected in supplemented mice (caproate, methyl butyrate, propionate, acetate and valerate) exceeded those concentrations detected in obese and lean controls except for butyrate. Despite the changes in microbial composition and in colon tissues and mucosal cells were similar in all obese mice with and without supplementation. This paper shows that dietary supplementation with cherry powder for 12 
47 weeks affects the microbiota and the concentrations of SCFAs in the lower intestinal tract of

48 obese $\mathrm{db} / \mathrm{db}$ diabetic mice. These effects occurred in absence of differences in most biomarkers

49

50

51

52

53

54

55

56

57

58

59

60

61

62

63

64

65

66

67

68

69

of inflammation and other parameters of gut health. Our study prompts more research into the potential clinical implications of cherry consumption as a dietary supplement in diabetic and obese human patients.

\section{Introduction}

The digestive tract of humans and other animals has coevolved over millions of years with a complex assemblage of many different types of microorganisms (gut microbiota). This coevolution has brought benefits to both forms of life, with the latter sustaining life in the former by helping regulate digestion of nutrients, behavior and the activity of the immune system (Conlon \& Bird, 2014). Importantly, some bacterial groups in the gastrointestinal tract have become specialized at surviving upon host-derived compounds (de Vos, 2017), while other groups are believed to be more dependent on dietary-derived compounds.

2 The membership of the gut microbiota (both at the mucus layer and in the lumen) is relatively constant overtime and resilient to change. However, this complex host-microbial ecosystem can also experience extensive variability (both over time within an individual or among different individuals) depending on a variety of factors including the age of the host, dietary patterns, body weight and physical activity. Expectably, diet has strong effects on different aspects of health (Palmer et al., 2017; Dahan et al., 2017) and a growing group of researchers have demonstrated that these effects are partly mediated by a change in the composition and/or the metabolic activity of the gut microbiota (Noratto et al., 2014; Garcia-Mazcorro et al., 2016a and 
70

71

72

73

74

75

76

77

2016b; Wu et al., 2011). Although there is still a lot of room for understanding and most studies have only analyzed the fecal microbiota, we now know that dietary modifications can change the composition and activity of the gut microbiota which in turn may promote wellbeing in the host (Sheflin et al., 2016; Velly et al., 2016).

Each type of food contain a specific blend of nutrients and other bioactive compounds that can be considered as part of medical strategies to help patients suffering with certain health disorders. Useful examples of these health disorders are obesity, diabetes and associated metabolic conditions (Via and Mechanick, 2016), which can be partly treated using foods with more fiber and/or chemical compounds such polyphenols and other anti-oxidants (Pérez-Jiménez et al., 2010). These bioactive compounds (i.e. anti-oxidants) have beneficial effects on health and growing evidence suggest that these effects are partly mediated by changes in the gut microbiota (Noratto et al., 2014; Rowland et al., 2017; Henning et al., 2017). The benefits of studying this topic are wide and include a better understanding of mechanisms of action thus widening the potential of certain foods to treat specific health disorders.

Cherries are fruits containing bioactive compounds with beneficial properties on human and animal health. Some well-studied cherries compounds include polyphenolics, carotenoids, and tocopherols (Budak 2017; Mikulic-Petkovsek et al., 2016; Redondo et al., 2017). Polyphenolics can influence health because of their anti-oxidative, anti-inflammatory, anti-mutagenic and anticarcinogenic properties (Panche et al., 2016). Despite the evidence in laboratory animals showing a potential of cherries to help patients with weight disorders (Wu et al., 2014; Song et al., 2016; Wu et al., 2016), and the likely involvement of the gut microbiota in this phenomenon 
93 (Faria et al., 2014), to our knowledge there are no studies that have investigated the effect of

94 cherry consumption on the gut microbiota using obesity models. Therefore, the objective of this

95 study was to investigate the effect of cherry supplementation on the gut microbiota, SCFAs and

96 biomarkers of gut health using an in vivo rodent model of obesity.

97

98 Material and methods

99 Study design

100 The experimental analyses carried out in this manuscript were approved by the Institutional 101 Animal Care and Use Committee at Texas A\&M University (IACUC 2013-0149). Two diets

102 were utilized in this study, one with and one without supplementation with dark sweet cherry 103 (Prunus avium) powder (Table 1 and Supplementary Table S1). Both diets were adjusted to 104 contain the same amount of energy (Table 1). Leptin receptor-deficient obese $\mathrm{db} / \mathrm{db}$ mice 105 (BKS.Cg-+Lepr ${ }^{\mathrm{db}} /+$ Lepr $^{\mathrm{db}} / \mathrm{OlaHsd}-$ fat, black, homozygous) received a diet without cherry 106 supplementation (obese control, $n=15)$ and with $10 \%$ cherry powder supplementation $(n=15)$.

107 Lean mice (BKS.Cg-Dock ${ }^{7 m}+/+$ Lepr $^{\mathrm{db}} / \mathrm{OlaHsd}-$ lean, black, heterozygous, $\mathrm{n}=10$ ) were used as 108 lean controls and fed a standard diet (i.e. without cherry supplementation, Table 1). All mice 109 were purchased from Envigo RMS, Inc. (Houston, TX). Agar based diets were prepared with 110 AIN-93G diet ingredients as reported in detail elsewhere (Noratto et al., 2016). The election of 111 an agar-based diet allowed fulfilling the food and part of the water requirement of mice and 112 preserved bioactive compounds in cherry because of the physical properties of agar that remains 113 liquid at $40-45^{\circ} \mathrm{C}$. Food and water were provided ad libitum every day for 12 weeks. Food 114 intake and waste were daily recorded. Body weight was recorded once a week and body mass 
115 indexes (BMIs) were calculated by dividing body weight $(\mathrm{kg})$ by body length $\left(\mathrm{m}^{2}\right)$ at the end of

116 the study (Jeyakumar et al., 2006).

117

118 Blood and tissue collection

119 Mice were terminated at week 12 after $\sim 12 \mathrm{~h}$ fasting by gradual exposure to $\mathrm{CO}_{2}$ inhalation until

120 the animal became unconscious, followed by cervical dislocation. Blood obtained by cardiac

121 puncture was collected into a tube containing $10 \mu \mathrm{L}$ of heparin and centrifuged at $10,000 \mathrm{rpm}$ at

$1224^{\circ} \mathrm{C}$ to obtain blood plasma. Blood plasma samples were aliquoted and frozen at $-80^{\circ} \mathrm{C}$ until

123 analysis. The transverse colon was removed and divided into three sections; one section was

124 fixed in 10\% neutral formalin buffer overnight and maintained in $70 \%$ ethanol at $4^{\circ} \mathrm{C}$ for

125 histological analysis of wall layer thickness (see below) while the other two sections were

126 cleaned from intestinal content with $100 \mathrm{mM}$ phosphate buffer solution $(\mathrm{PBS}, \mathrm{pH}=7)$ and either

127 kept in RNA later ${ }^{\circledR}$ (Applied Biosystems, Foster City, CA) or subjected to scraping the mucosa

128 off and kept in RNA later ${ }^{\circledR}$ (named colonic mucosal cells). Samples maintained in RNA later ${ }^{\circledR}$

129 were stored at $-80^{\circ} \mathrm{C}$ for further analysis.

130

131 Bioactive compounds in cherry powder

132 Dietary fiber was quantified by Retch laboratories (Arden Hills, MN) following standard

analytical protocols. Total extractable phenolics were extracted as previously reported (Condezo-

134 Hoyos et al., 2014). Briefly, cherry powder (0.5 g) was homogenized with $3 \mathrm{~mL}$ acidic methanol

$135(\mathrm{HCl}) /$ water solution $(50: 50 \mathrm{v} / \mathrm{v}, \mathrm{pH} 2)$ and left for $1 \mathrm{~h}$ at room temperature and constant shaking,

136 followed by centrifugation at $4000 \mathrm{x}$ g for $10 \mathrm{~min}$ at $4^{\circ} \mathrm{C}$ to obtain the acid methanolic extract in

137 the supernatant. The precipitate was extracted with $3 \mathrm{~mL}$ of acetone/water solution $(70: 30 \mathrm{v} / \mathrm{v})$ 
$138(1: 5 \mathrm{ratio}, \mathrm{v} / \mathrm{v})$ by agitation for $1 \mathrm{~h}$ at room temperature, followed by centrifugation at $4000 \mathrm{xg}$

139 for $10 \mathrm{~min}$ at $4^{\circ} \mathrm{C}$ to obtain the acetone extract in the supernatant. The combined supernatants

140 were analyzed for total extractable phenolics by Folin Ciocalteu method (Condezo-Hoyos et al.,

$1412014)$, using a standard curve of gallic acid ( 0 to $0.2 \mathrm{mg} / \mathrm{mL}$ ) and expressed as gallic acid

142 equivalents (GAE). The residues were subjected to alkali treatment for extraction of non-

143 extractable or bound phenolics as reported (Luo et al., 2016). Briefly, $3 \mathrm{~mL}$ of $\mathrm{NaOH}(4 \mathrm{M})$ were

144 added to residues after extractable phenolics were recovered and maintained in agitation for $2 \mathrm{~h}$

145 under nitrogen atmosphere in a screw capped vial, followed by centrifugation at $4000 \mathrm{x} g$ for 10

$146 \min$ at $4^{\circ} \mathrm{C}$. The recovered supernatant was adjusted to $\mathrm{pH} 2$ with $\mathrm{HCl}(6 \mathrm{M})$ and analyzed for

147 non-extractable bound phenolics using the Folin Ciocalteu method (Condezo-Hoyos et al., 2014).

DNA extraction

150 Colon content and colonic mucosal samples scrapped from terminal colon were collected from 151 all mice at the end of the study and used to purify total genomic DNA using a commercial DNA 152 extraction kit (Zymo Research Corp, Irvine, CA, USA). DNA samples were adjusted to $5 \mathrm{ng} / \mu \mathrm{L}$ 153 and used for two different analyses (high-throughput 16S sequencing and qPCR analyses).

155 High-throughput 16S sequencing for colonic microbiota

156 DNA samples extracted from terminal colon contents were used to amplify a small ( $\sim 300 \mathrm{bp})$

157 fragment of the 16S rRNA gene using the primers F515 (5'-GTGCCAGCMGCCGCGGTAA$\left.1583^{\prime}\right)$ and R806 (5'-GGACTACHVGGGTWTCTAAT-3') for further high-throughput sequencing 159 as shown elsewhere (Garcia-Mazcorro et al., 2016a). PCR reactions and 16S sequencing were 160 performed at the Molecular Research LP (MRDNA, Shallowater, Texas USA). The MiSeq 
161 instrument (Illumina) was used for sequencing the 16S amplicons following the manufacturer's

162 instructions at MRDNA. This technology has been used in several studies and is recommended

163 by the Earth Microbiome Project (Caporaso et al., 2012). Raw 16S data was obtained from

164 MRDNA and analyzed using the freely available bioinformatics pipeline QIIME v.1.8 with

165 default parameters. MRDNA conveniently provides users with files containing joined reads

166 (full.fasta and full.qual files). These files were combined in one single fastq file using QIIME.

167 The resulting fastq file was then used to split sample libraries accordingly to the 8 nucleotide

168 barcodes using the split_libraries_fastq.py in QIIME. Operational Taxonomic Units (OTUs) are

169 operational definitions used to classify $16 \mathrm{~S}$ rRNA gene sequences from related and unrelated

170 microorganisms and there is debate regarding the best approach to select OTUs from $16 \mathrm{~S}$

171 sequences (He et al., 2015). In this study we used two approaches to select OTUs. First, we used

172 an open reference algorithm (Rideout et al., 2014), which has the advantage of not discarding

173 sequences that do not match the sequence database. The OTU table generated by this approach

174 was used for all diversity and taxonomic analyses. Second, we used a closed reference approach

175 where sequences are discarded if they do not have a close match with the reference sequences.

176 The OTU table generated using this closed approach was used for predicting functional profiles

177 using PICRUSt (see Prediction of metabolic profile below). In this study we used the v. 13_5 of

178 the GreenGenes OTU representative 16S rRNA sequences as the reference sequence collection

179 (DeSantis et al., 2006). The phylogenetic method UniFrac (Unique Fraction metric, Lozupone

180 and Knight, 2005) was used to investigate differences in microbial communities. Please note that

181 it is important to investigate both quantitative (weighted) and qualitative (unweighted) UniFrac

182 diversity measures because they can lead to different insights into the factors responsible for

183 structuring microbial communities as shown elsewhere (Lozupone et al., 2007). All sequence 
184 data and associated metadata was uploaded into the Sequence Read Archive at the NCBI 185 (SRP117747).

186

187 qPCR for colonic microbiota and for colonic mucosal samples

188 Unlike high-throughput sequencing (which in this study was only used to analyze the microbiota 189 in colon contents), DNA samples from both colon contents and from colon mucosal samples 190 were used to perform quantitative real-time PCR (qPCR) using primers targeting the 16S rRNA 191 genes for specific groups of microorganisms (Supplementary Table S2) based on the Gut Low192 Density Array (GULDA, Bergström et al., 2012) approach and other publications (Garcia193 Mazcorro et al., 2012; Noratto et al., 2014; Yang et al., 2015). All qPCR reactions were carried 194 out at Texas A\&M University using the described methodology by Bergström et al. (2012) with 195 modifications. Briefly, in this study all assays were ran using a standard curve and these standard 196 curves were constructed using different concentrations of DNA from either the specific 197 microorganisms (Bacteroides fragilis, Lactobacillus plantarum NRRL No B-4496, E. coli NRRL 198 No B-766) or from samples containing high amounts of the desired organism (e.g. a standard 199 curve for Ruminococcaceae was constructed using serial dilutions of a sample with high amounts 200 of Ruminococcaceae DNA as determined by qPCR). DNA samples were adjusted to $5 \mathrm{ng} / \mu \mathrm{L}$.

201 qPCR data is expressed as log amount of DNA (picograms of amplified DNA) for each bacterial 202 group per $10 \mathrm{ng}$ of total DNA (Bell et al., 2014).

204 Prediction of metabolic profile

205 Phylogenetic investigation of communities by reconstruction of unobserved states (PICRUSt, 206 Langille et al., 2013) was used to predict the metabolic profile based on 16S sequencing data. 
207 For this analysis, we used the OTU table obtained from the closed reference approach described

208 above. PICRUSt results were visualized and analyzed using STAMP (Parks and Beiko, 2010)

209 with default parameters. PICRUSt analysis was performed using the OTU table containing all

210 taxa (full OTU table) and also using filtered OTU tables containing a subset of taxa to explore

211 contributions of different taxa separately.

212

213 Short-chain fatty acids (SCFA) analysis

214 Caecal contents were homogenized with MilliQ water in a proportion of 1:1.5 (weight:volume)

215 and centrifuged at $12000 \mathrm{~g}$ for $10 \mathrm{~min}$. Supernatants were then filtered through a $0.45 \mu \mathrm{m}$ Nylon

216 filter (VWR ${ }^{\circledR}$ Syringe Filters, Houston, TX) and analyzed by high-performance liquid

217 chromatography (HPLC) as reported in detail elsewhere (Campos et al. 2012; Garcia-Mazcorro

218 et al., 2016a). Butyric acid, methyl-butyric acid, caproic acid, sodium acetate, sodium

219 propionate, and valeric acid were purchased from VWR and used as standards to quantify their

220 caecal contents based on retention time and area of peaks at $\lambda=220 \mathrm{~nm}$.

221

222 Histological analyses of colon tissue sections

223 Paraffin-embedded colon tissues were transversally cut (5 $\mu \mathrm{m}$ thickness) and stained with H\&E

224 for microscopic analysis. The thickness of outer colon wall layer was calculated in ImageJ

225 (http://rsb.info.nih.gov/ij/) using 10 measurements (ratio of outer colon wall area to total (outer

226 and inner) colon wall area) from each individual mouse. Photomicrographs were taken with

227 Aperio CS2 digital pathology scanner (Leica Biosystems Inc, Buffalo Grove, IL, USA) and

228 blinded analyzed with regards to treatment group. 
230 Endotoxin levels in caecal contents and plasma

231 Caecal contents and blood plasma were subjected to endotoxin analysis using the Endpoint

232 Chromogenic LAL Assay following the manufacturer's protocol (Lonza Walkersville, Inc. -

233 Walkersville, MD). Briefly, caecal contents were weighted, suspended in milliQ water (1:1.5,

$234 \mathrm{~W}: \mathrm{v})$, centrifuged at $12000 \mathrm{~g}$ for $10 \mathrm{~min}$ and supernatants transferred to a glass vial for

235 endotoxins quantification. Endotoxin units (EU) were calculated as EU/mg caecal content.

236

237 mRNA levels in colonic tissue and mucosal cells

238 Biomarkers of inflammation, cellular stress, and gut barrier function were analyzed in colonic

239 tissue and mucosal cells. Briefly, tissues or scrapped mucosal cells were mechanically pulverized

240 in liquid nitrogen. RNA was extracted using TRIzol® LS Reagent (Life technologies, Carlsbad,

241 CA) according to the manufacturer's protocol. Purification was carried out with Direct-zol ${ }^{\mathrm{TM}}$

242 RNA MiniPrep (Zymo Research Corp, Irvine, CA) according to the manufacturer's protocol.

243 Quantification of mRNA was performed using the ND-1000 spectrophotometer (Nanodrop

244 Technologies, Rockland, DE). Purified mRNA was used to synthesize cDNA using iScript ${ }^{\mathrm{TM}}$

245 cDNA Synthesis Kit (BioRad, Hercules, CA). Quantitative real-time polymerase chain reaction

246 (qRT-PCR) was carried out with the SsoAdvanced ${ }^{\mathrm{TM}}$ Universal SYBR® Green Supermix

247 (BioRad, Hercules, CA) on a CFX384 Touch Real-Time PCR Detection System (BioRad,

248 Hercules, CA). The reaction volume was $10 \mu \mathrm{L}$ and all primers were used at a final

249 concentration of $100 \mathrm{nmol} / \mathrm{L}$. The RT-PCR data was analyzed by the $2-\Delta \Delta \mathrm{CT}$ method in

250 reference to ribosomal protein L19 (RPL19) as housekeeping gene (Schmittgen and Livak 2008).

251 Primers were purchased from Integrated DNA Technologies, Inc. (San Diego, CA,

252 Supplementary Table S3). Product specificity was examined by dissociation curve analysis. 
254 Statistical analysis

255 Relative abundances of taxa based on sequencing data, mRNA expression, and qPCR data were 256 compared using the non-parametric Kruskal-Wallis test and multiple comparisons were adjusted 257 using Bonferroni in PAST (Hammer et al., 2001). PAST was also used to perform Principal 258 Coordinate Analysis (PCoA) using the weighted and unweighted UniFrac distance matrices 259 obtained from QIIME. The Kruskal-Wallis test was also used for comparison of predicted 260 functional features in STAMP (Parks and Beiko, 2010). The non-parametric ANOSIM and 261 Adonis tests were performed for determining whether the grouping of samples by a given

262 category is statistically significant in QIIME. Spearman's correlations matrices featuring data 263 from sequencing analyses, SCFAs, and mRNA levels in colonic mucosal cells identified by 264 Kruskal-Wallis test as significant $(\mathrm{p}<0.05)$, were performed using R studio 3.4.0. SCFAs were 265 compared using the Mann Whitney test when comparing only two treatment groups due to lack 266 of detectable values in one group.

\section{Results}

Cherry powder contributed with phenolics and dietary fiber as bioactive compounds that might reach the lower intestinal tract because of their low bioavailability and most likely modulate microbial populations in the large intestine. Cherry powder had 5.1\% fiber and $759 \mathrm{mg}$

272 GAE/100g of total phenolics (Table 1). A recent study has thoroughly analyzed the profile of phenolics in dark sweet cherry varieties using mass spectrometry and reported approximately 86 compounds including phenolics, anthocyanins, flavan-3-ols and flavonols (Martini et al., 2017). 
276

277 Several obese animals died for reasons unrelated to the study (five animals from obese control

278

279

280

281

282

283

284

285

286

287

288

289

290

291

292

293

294

295

296

297

298

Host physiology

group, three animals from cherry group), all other mice remained visually healthy throughout the study. Body weight, BMIs, the percentage of adiposity, epidydimal and mesenteric fat as well as liver weight were similar in all obese mice (with and without cherry supplementation) and significantly higher compared to lean controls (Supplementary Table S4). The weight of cecum contents was significantly higher in cherry supplemented mice (314 mg, 198-439 mg, median and interquartile ranges respectively) compared to lean (128 mg, 93-152 mg) and obese controls (191 mg, 104-234 mg) ( $p=0.003$, Supplementary Table S4), in part reflecting the higher amount of fiber in the cherry-supplemented diet (Table 1).

\section{High-throughput $16 \mathrm{~S}$ sequencing for colonic microbiota}

High-throughput $16 \mathrm{~S}$ sequencing allows a deep analysis of complex microbial communities such as the gut microbiota. In this study, the split libraries script yielded a total of 3,171,568 goodquality $16 \mathrm{~S}$ sequences for analysis ( $\mathrm{n}=32$ across all treatment groups, median sequence length: 300 nucleotides). The number of sequences per sample varied from 61,284 (lowest) to 142,829 (highest). All analyses were performed using a rarefaction depth of 61,000 sequences per sample.

94 Overall the colonic microbiota was dominated by six main taxa at the order level representing four phyla: Bacteroidales (phylum Bacteroidetes), Clostridiales and Lactobacillales (phylum Firmicutes), Verrucomicrobiales (phylum Verrucomicrobia), Desulfovibrionales and Enterobacteriales (phylum Proteobacteria). Together, these taxa comprised about 20 different bacterial families which accounted for over $95 \%$ of all sequences in most samples (Figure 1). 
299 The results of sequencing and/or qPCR showed significant differences in the relative abundance

300 of several members of all these main taxa in supplemented mice.

301

302 The phylum Bacteroidetes contains several bacterial groups associated with health and this group

303 is usually highly abundant in feces and intestinal contents of human and laboratory mice

304 (Karlsson et al., 2010). The family S24-7 (a group of fiber degraders) was very similar in lean 305 (median=19.8\%) and cherry-supplemented (median=20.3\%) and both were about 3 times higher 306 when compared to obese mice (median=7.9\%, $<<0.005$ for both comparisons) (Figure 1). While 307 this result supports the observed higher weight of cecum contents in supplemented mice, it also 308 opens up the question of why lean controls (not supplemented) also showed similar levels of 309 S24-7 compared to supplemented mice. The family Bacteroidaceae was similar in all obese mice 310 but only supplemented mice had higher abundance (median=13.5\%) compared to lean controls

311 (median $=6.6 \%, \mathrm{p}=0.0124$ ). This is interesting because Bacteroides has been linked to production 312 of SCFAs (Chen et al., 2017; Rios-Covian et al., 2017) and at least one group of Bacteroides (B. 313 acidifaciens) has been shown to also use host compounds (Berry et al., 2013; Sonnenburg et al., $3142005)$ similarly to Akkermansia.

316 The phylum Firmicutes is also a highly abundant member of the gut microbiota and contains 317 many groups associated with health, for example producers of SCFAs (Barcenilla et al., 2000). 318 Interestingly, we did not find any difference in the abundance of the two most abundant families 319 within the Firmicutes: Ruminococcacea and Clostridiaceae. On the other hand, Lactobacillus 320 was much lower ( $\sim 10$ times lower) in cherry-supplemented mice (median $=0.8 \%)$ compared to 321 both lean $($ median $=12.4 \%)$ and obese (median=13\%) controls $(\mathrm{p}<0.005$ for both comparisons), a 
322 finding that was also noticeable at the family level (Figure 1) and that was confirmed using

323 qPCR (see qPCR below).

324

325 The phylum Verrucomicrobia is usually low in abundance in the lower gut but it also contains

326 important bacterial groups that have been associated with health such as the mucin-degrader

327 Akkermansia (Derrien et al., 2008). In this study, the genus Akkermansia (family

328 Verrucomicrobiaceae) was lower in obese mice (median=0.07\%) compared to lean

329 (median $=0.31 \%, p=0.0402)$ but especially to cherry-supplemented mice (median $=4.9 \%$,

$330 \mathrm{p}=0.0003$ ), a result that was also confirmed by qPCR. This result was also confirmed using

331 qPCR (see qPCR below).

332

333 The phylum Proteobacteria (main order Enterobacteriales) contains bacteria that are usually

334 associated with harmful effects on intestinal health such as several strains of Escherichia and

335 Salmonella. In this study, the family Enterobacteriacea was more similar between lean

336 (median $=0.08 \%$ ) and cherry-supplemented (median=0.3\%) mice and both were much lower

337 compared to obese mice (median $=7.3 \%, \mathrm{p}<0.05$ for both comparisons, Figure 1 ), a finding that

338 could be considered a positive effect of cherry supplementation. The lower abundance of

339 Enterobacteriaceae in supplemented mice was also confirmed using qPCR (see qPCR below). In

340 this study Enterobacteriaceae was the only family within the order Enterobacteriales but most

341 sequences belonged to an unknown genus. The family Alcaligenaceae (Betaproteobacteria) was

342 higher in supplemented mice (median=1.1\%) compared to both lean (median=0.06\%) but

343 especially to obese (median $=0.01 \%$ ) controls $(\mathrm{p}<0.005$ for both comparisons). There was no

344 significant difference in the abundance of Desulfovibrionales (class Deltaproteobacteria). 
346 Finally, the family Bifidobacteriaceae (order Coriobacteriales, phylum Actinobacteria) was not

347 detected at all with our sequencing effort. Nonetheless, supplemented mice showed similar

348 abundance of the order Coriobacteriales (median $=0.1 \%$ ) compared to lean (median=0.3\%) but

349 only lean mice was higher compared to obese (median $=0.08 \%, \mathrm{p}<0.0001)$.

350

351 Alpha diversity analyses

352 The comparison of relative abundances help determine differences in groups of microorganisms

353 (e.g. Akkermansia) but it does not help shed light into the diversity of microbial life among the

354 different samples. Interestingly, cherry-supplemented mice showed the highest Shannon

355 diversity indexes (index $=8.1)$ compared to both obese (index $=7.4$ ) and lean controls (index=6.9, $356 \mathrm{p}=0.0141$ Kruskal-Wallis). Also, the number of species (OTUs at 97\% similarity) was higher in 357 obese controls (5407) and lower in lean (4078), with supplemented mice having intermediate 358 values (4838, $\mathrm{p}=0.0078$, Kruskal-Wallis test) but overall the number of OTUs did not reach a 359 plateau for any treatment group, particularly in obese mice with and without cherry (Figure 2).

360 This means that the sequencing effort in this study was not enough to fully describe the total

361 number of species in our samples; however, it is important to remember that these OTU

362 measures were obtained from an open OTU picking approach that does not discard sequences 363 based on matching with reference database.

Beta diversity analyses

366 The analysis of individual taxa such as Akkermansia or Lactobacillus yields valuable information

367 about the membership of the bacterial communities; however, the differences in individual taxa 
368 may or may not be sufficient to generate a distinctive microbial community. Using weighted

369 UniFrac distances (which takes into account both phylogenetic divergence and the numbers of

370 sequences associated with each OTU), there was a significant clustering of samples according to

371 treatment $(\mathrm{p}<0.001$, Adonis test; $\mathrm{p}=0.001, \mathrm{R}=0.716$, ANOSIM test) (Figure 3). There was also a

372 significant difference using unweighted UniFrac ( $\mathrm{p}<0.001$, Adonis test; $\mathrm{p}=0.001, \mathrm{R}=0.844$,

373 ANOSIM test), which does not take into account the number of OTUs (Figure 3). Please note

374 that these tests often have a low sensitivity (they usually detect a difference when there is none),

375 therefore it is also informative to look at the R values in the ANOSIM test to investigate the

376 strength of clustering (the closest to 1 the strongest the clustering of samples). Therefore, the

377 higher R value in the ANOSIM test for the unweighted UniFrac implies that the clustering is

378 stronger compared to the clustering using weighted UniFrac, meaning that each treatment is

379 mainly associated with phylogenetic distinct bacterial populations rather than the numbers of

380 these populations. This result can easily be appreciated in the PCoA plots of UniFrac metrics

381 (Figure 3).

382

383 Predicted metabolic profile

384 PICRUSt is useful at predicting the metabolic profile of the microbiota based on 16S sequencing data. In this study, a great number of features showed statistical significance among treatment groups (Table 2), especially within metabolism and genetic information processing pathways. In our experience, these differences are not due to stochastic variations (e.g. other studies from our research group have shown no differences in any feature using a very similar methodological approach, Garcia-Mazcorro et al., 2017). Interestingly, for almost all features cherrysupplemented mice showed abundances that were in between those abundances in obese and lean 
391 controls (Table 2). Lean mice had higher weighted Nearest Sequenced Taxon Index (weighted

392 NSTI) scores compared to obese controls and supplemented mice ( $p<0.05$ for both comparisons),

393 meaning that the microbiota of all obese mice was relatively more represented in sequenced

394 genomes.

395

396 The feature with the lowest $p$ value in PICRUSt analysis was associated with terpenoid backbone 397 biosynthesis (adjusted $\mathrm{p}=0.0003$ ), with lean controls having the highest (average: $0.69 \%$ ) and 398 obese controls the lowest $(0.54 \%)$ values, with supplemented mice having values in between $399(0.61 \%)$. This topic is interesting because terpene synthases are widely distributed in bacteria 400 (Yamada et al., 2015) and terpenes have beneficial properties in human health (Cho et al., 2017); 401 however, there is little information about the potential of terpene synthesis in the gut microbiota. 402 In order to investigate what bacterial group was more associated with this difference, we 403 performed PICRUSt on different taxa independently using filtered OTU tables. There was a 404 difference in this feature for the phylum Firmicutes and Bacteroidetes but all obese mice (with 405 and without supplementation) showed very similar abundances compared to lean, suggesting that 406 the group responsible for the overall effect on terpenoid backbone biosynthesis was not a 407 member of either phylum. Interestingly, the independent analysis of Proteobacteria revealed that 408 lean controls had the highest (average: $0.51 \%$ ) and the obese controls the lowest values (average: 409 $0.39 \%$ ) with supplemented mice somewhere in between (average: $0.45 \%$ ), a result that is similar

410 to the analysis of all bacterial groups at once. This suggests that a member of Proteobacteria was

411 likely associated with the observed difference in the abundance of genes associated with

412 terpenoid backbone biosynthesis. However, the independent analysis of individual taxa within

413 the Proteobacteria did not yield any useful information with regards to any specific taxa 
414 associated with the overall difference in terpenoid backbone biosynthesis, suggesting that this

415 difference was due to the combined contribution of several bacterial groups. This area is indeed

416 worth exploring because terpenoids can work as antibiotics and growing research show that

417 commensal microorganisms can generate potent small molecules (Modi et al., 2014). Doing this

418 additional analysis for all features that showed statistical significance (Table 2) is advisable but

419 is outside of the scope of this present manuscript.

420

421 qPCR analyses

422 In this study we performed qPCR analyses using DNA from both colon contents and mucosal

423 samples. Using DNA obtained from samples of colon contents, several qPCR results confirmed

424 the sequencing results (Figure 4). For example, Lactobacillus was found to be lower in cherry-

425 supplemented mice compared to both lean and obese controls $(p<0.0001)$. Similarly,

426 Akkermansia was lower in obese mice compared to lean and cherry supplemented $(\mathrm{p}<0.0001$,

427 Kruskal Wallis test) and this result was mainly due to a difference between the obese control

428 group and the cherry-supplemented group ( $<<0.0001)$ (Figure 4). Also, Enterobacteriaceae were

429 lower in cherry-supplemented and lean mice compared to obese controls. Using qPCR we were

430 able to show that $E$. coli was also lower in supplemented mice, a finding that we could not

431 investigate using sequencing. Moreover, Betaproteobacteria was higher in cherry-supplemented

432 compared to lean and obese controls $(\mathrm{p}<0.0001)$. Please note that the family Alcaligenaceae

433 within the Betaproteobacteria also showed similar differences using sequencing. qPCR results

434 for colon contents also showed that the abundance of Bifidobacterium was higher in

435 supplemented mice compared to obese $(\mathrm{p}<0.0001)$ and lean $(\mathrm{p}=0.002)$ controls (Figure 4$)$. These

436 results were partly confirmed using sequencing at higher taxonomic levels (order 
437 Coriobacteriales, see Colonic microbiota above). C. butyricum (a butyrate-producing

438 microorganism, Zhang et al., 2009) was also found to be higher in supplemented mice (Figure $4394)$.

440

441

qPCR analysis of the mucus-associated microbiota helped shed light into an area that is not

442 usually evaluated (most studies evaluate either feces or intestinal contents in part due to ease of

443 sampling and amount of material for analysis). Unfortunately, we only obtained results from four

444 bacterial groups because the results from all other bacterial groups (Akkermansia included) were

445 either undetectable or fell below the lowest standard. This can be explained by the fact that

446 commensal bacteria have their habitat in the outer colonic mucus layer, which can be easily lost

447 during tissue dissection and washing (Johansson et al., 2008). However, opportunistic pathogens

448 have developed mechanisms to secrete proteases that cleave mucin allowing certain bacteria

449 penetrate and reside in the inner mucus layer (Pelaseyed et al., 2014). Interestingly, in this study

450 we found patterns of variations in colon mucosal cells that were not in agreement with those

451 variations observed in colon contents. For example, Betaproteobacteria and Enterobacteriaceae

452 were found to be lower in lean mice compared to all obese mice with and without cherry

453 supplementation (Figure 4). On the other hand and similarly to qPCR results in colon contents,

454 C. butyricum was also higher in supplemented mice and Bacteroidetes also showed similar

455 results compared to qPCR results from colon contents (Figure 4).

457 SCFA in caecal contents

458 SCFA are microbial metabolites that have been associated with health and disease. In this study,

459 the SCFAs detected in cherry-supplemented mice (caproate, methyl butyrate, propionate, acetate 
460 and valerate) exceeded those concentrations detected in obese and lean controls except for

461 butyrate, either because of higher values or because of higher number of samples in which the

462 SCFAs were detected (Table 3). This is relevant because SCFAs are substrates for colonocytes

463 providing at least 60-70\% of their energy requirements (Suzuki et al., 2008) with implications

464 for gut barrier function. Based on these results, cherry dietary supplementation contributes with

465 fiber and phytonutrients that apparently promotes a healthier SCFA-producing microbiota, thus

466 contributing to improve colon barrier function and reduce the risk of inflammatory diseases (Tan

467 et al., 2014).

468

469 Outer colon wall thickness

470 In this study, the median ratio outer colon wall to total colon wall was higher in supplemented

471 mice $($ median $=0.73)$ and lean mice $($ median=0.72) compared to obese controls $($ median=0.64)

472 but this difference did not reach significance $(p=0.08)$ due to the variability among animal

473 subjects (Supplementary Fig. S1). Increased intestinal concentrations of SCFAs in supplemented

474 mice might have contributed to increase the height of intestinal outer wall layer (Ramos et al., 475 1997).

476

477 Biomarkers of inflammation, cellular stress, and gut barrier function in colon tissue and colonic 478 mucosal cells

479 The colon mucus layers and enterocytes provide the first defense line of the gastrointestinal tract.

480 We have analyzed the mRNA levels of biomarkers of inflammation, cellular stress, and gut

481 barrier function in mucosal cells and colon tissues as a tool to assess whether the changes

482 promoted in gut microbiota by cherry bioactive compounds might also trigger differentiated 
483 responses in the host gate keepers (mucosal layer and epithelial cells) with possible implications

484 in host-bacterial interactions and host immune system. Despite the differences in microbiota and

485 SCFAs, most of the biomarkers analyzed in colonic mucosal cells were similar between

486 experimental groups (Supplementary Table S5), and no difference was found in biomarkers

487 assessed in colon tissues (Supplementary Table S6). In colonic mucosal cells only ATF4 mRNA

488 levels were significantly lower in supplemented group compared to lean $(p<0.05)$, and tended to

489 be lower than in obese control. ATF4 is a stress-induced transcription factor whose expression

490 has been correlated with degree of intestinal inflammation and development of inflammatory

491 bowel diseases in adults (Negroni et al., 2014). Likewise, VCAM-1, known to control leukocyte/

492 monocyte intestinal recruitment and localization in LPS-induced inflammation (Totsuka et al.,

493 2014), were lower in supplemented group than obese and lean controls, but did not reach

494 significance $(\mathrm{p}=0.06)$ (Supplementary Table S5).

495

496 The concentrations of LPS measured as EU in caecal contents and blood plasma showed no

497 significant difference among experimental groups. However, the LPS concentrations in lumen

498 were not determined due to limitations in sample availability used for DNA extractions and

499 microbiota analysis. Thus, LPS in caecal contents might not necessarily correlate with the LPS

500 concentrations in lumen. We could speculate LPS was lower in supplemented group, thus

501 explaining the lower ATF4 mRNA levels.

502

503 Correlation analysis

504 The separate analyses of microbiota, SCFAs and mRNA levels yielded useful information with

505 regard to the effect of dietary interventions but this data must be integrated in an effort to find 
506 possible biologically relevant associations. Overall, data from 16S rRNA sequencing was highly

507 correlated with data from qPCR (Supplementary Figure S2), as discussed above. Interestingly, a

508 high positive correlation was observed between Bacteroides and Akkermansia, while a negative

509 correlation between Bacteroides and Lactobacillus was observed. It is also worth mentioning

510 that samples from supplemented mice were associated with higher levels of SCFAs and more

511 Akkermansia, an interesting relationship given the production of SCFAs by this bacterial group

512 (Belzer and de Vos, 2016).

513

514 Discussion

515 Diabetes and obesity are complex diseases that can often be treated using a combination of

516 medications, dietary modifications and physical exercise. Cherries contain fiber and bioactive

517 compounds such as polyphenolics that can promote wellbeing in the host. This study describes

518 the effect of cherry consumption on the colonic microbiota, short-chain fatty acids, and

519 biomarkers of intestinal health using an in vivo model of genetic obesity.

520

521 The metabolism and pharmacokinetics of cherry bioactive compounds inside the host are

522 important to evaluate any possible effect of a dietary intervention with cherry. A recent study

523 showed evidence suggesting an involvement of glucose transporters in the small intestine (such

524 as the sodium-dependent linked transporter) in the absorption of anthocyanins from bilberries but

525 it also highlighted the wide differences in bioavailability among different types of anthocyanins

526 (Baron et al., 2017). The amount and chemical characteristics of any post-digestion bioactive

527 compounds that reach the large intestine also varies depending on several factors. Importantly,

528 these bioactive compounds are often transformed throughout the digestive tract and reach the 
529 lower intestine in a modified form (Stalmach et al., 2010). It has been shown that the amount of

530 material reaching the colon is considerable and some authors even catalogue some of these

531 compounds as prebiotics because of its effect in the abundance of certain microorganisms (Cires

532 et al., 2017). Please note that prebiotics are historically considered to be non-digestible fiber and

533 that the increase in abundance of a certain group of microorganisms (e.g. Lactobacillus) when

534 exposed to anti-oxidants may or may not involve direct feeding on the compounds such as in the 535 case of dietary fiber. This is further complicated in case of cherries which contain both fiber and 536 considerable amounts of polyphenolics (McCune et al., 2011; Wang et al., 2017).

537

538 This study showed strong evidence that cherry supplementation can modify the colon

539 microbiota, a phenomenon that may be related to the fiber and/or to any post-digestion bioactive 540 compounds reaching the lower intestinal tract. For example, this study showed that the levels of 541 Akkermansia spp. in colon contents were higher in supplemented mice compared to both obese 542 and lean controls. Akkermansia is a common and relatively abundant ( $\sim 1 \%)$ anaerobic member

543 of the gut microbiota (Derrien et al., 20008) that is supposedly highly specialized in host-

544 compounds that may not compete with the microbiota in the highly populated lumen and

545 therefore do not depend on nutrients from host food consumption (Derrien et al., 2011).

546 Akkermansia indeed deserves attention because of its potential role as mediator of improved

547 inflammatory and metabolic phenotype of mice (Caesar et al., 2015). Interestingly, it has been

548 shown that the abundance of Akkermansia is lower in the intestinal epithelium of patients with

549 Inflammatory Bowel Disease (Png et al., 2010) and in feces often negatively correlates with

550 body weight in rodents and humans (the higher the body weight the lower the abundance of

551 Akkermansia, Everard et al., 2013). Another study showed that human subjects with higher $A$. 
552 muciniphila abundance in feces exhibited the healthiest metabolic status (Dao et al., 2016).

553 Therefore, members of this taxon have been suggested as biomarkers for a healthy intestine (Png

554 et al., 2010; Swidsinski et al., 2011). Accordingly, in this study we showed that cherry

555 supplementation was associated with increases the abundance of this health-bearing

556 microorganism, suggesting a beneficial effect of cherry consumption on health. Other similar

557 studies from our research group have also showed that obese mice have less Akkermansia

558 compared to lean and quinoa-supplemented obese mice (Garcia-Mazcorro et al., 2016a), and

559 others have shown that Akkermansia is higher during prebiotic administration (Everard et al.,

560 2011; Van den Abbeele et al., 2011).

561

562 The reasons behind any increase or decrease of bacterial groups in colon contents are often

563 difficult to clarify. While there may be several explanations for this phenomenon, in the case of

564 Akkermansia it has been shown showed that the accompanying microbiota composition

565 determines the magnitude and pattern of host-compounds foraging by this group (Berry et al.,

566 2013), an interesting phenomenon that has also been shown in other bacteria such as

567 Bifidobacterium (Klaassens et al., 2009). Importantly, it has been shown that Akkermansia is

568 actually composed by at least eight different species based on the 16S rRNA gene (van Passel et

569 al., 2011). This heterogeneity may explain why in other studies the abundance of Akkermansia

570 was not necessarily related with health status (Garcia-Mazcorro et al., 2016b; Noratto et al.,

571 2014). In fact, Akkermansia was shown to be increased in mouse studies of dextran sodium

572 sulfate (DSS)-induced colitis (Berry et al., 2012; Kang et al., 2013; Hakansson et al., 2015) and

573 can seemingly aggravate Salmonella enterica Typhimurium-induced gut inflammation in a

574 gnotobiotic mouse model (Ganesh et al., 2013). This phenomenon has been explained by an 
575 outgrowth of Akkermansia in response to the thickening of the mucus layer (Ottman et al., 2017)

576 but it fails to explain the rise of this group in intestinal contents. Given the potential existence of

577 different species of Akkermansia (van Passel et al., 2011), it is fair to speculate that at least some

578 of these species can use dietary substrates (instead or in addition to host-compounds) and

579 proliferate in the intestinal lumen, thus explaining the rise in numbers. On the other hand, feces

580 also contain abundant mucus (Swidsinski et al., 2008), therefore it is also possible that the

581 overgrowth of Akkermansia in the mucus layer simply leaked into the lumen.

582

583 Other bacterial groups aside Akkermansia deserve attention. For example, this study also showed

584 that a group of fiber degraders (the S24-7 family) was also higher in the supplemented group, a

585 finding likely related to the fiber contributed by the cherry-supplemented diet. The genomes of

586 several members of this S24-7 family have been recently explored showing that it contains three

587 trophic guilds, each broadly defined by differential abundances of enzymes involved in the

588 degradation of specific carbohydrates (plant, host and $\alpha$-glucan) (Ormerod et al., 2016).

589 Interestingly, cherry consumption was also associated with lower levels of Lactobacillus (a

590 commonly health-bearing group of bacteria) and Enterobacteriaceae (a group comprising

591 potential pathogens). While the reason behind these changes are likely related to the complex

592 microbial-host milieu, a recent study showed that these two groups (both Lactobacillus and

593 Enterobacteriaceae) were positively correlated to high levels of Salmonella-induced

594 inflammation (Borton et al., 2017).

595

596 This study showed that the differences in bacterial populations in the supplemented group were

597 accompanied by concentrations of SCFAs that generally exceeded those concentrations in lean 
598 and obese controls except for butyrate, an interesting finding because it is precisely butyrate that

599 has caught more attention from the scientific community. Butyrate is produced and also

600 transformed by the gut microbiota; however in our study the increased concentrations of methyl

601 butyrate (a methyl ester of butyric acid) in the supplemented group might be associated with the

602 presence of this ester in cherries as occurs in many plant products. This might be an advantage

603 over production of butyrate because the latter is rapidly metabolized and has limited clinical

604 efficacy in contrast with methyl butyrate which is less polar and less susceptible to being cleared

605 by the body (Khan et al., 2016). On the other hand, methyl butyrate may also be produced as a

606 by-product of bacterial metabolism. For example, in one study high production of methyl

607 butyrate was the most significant change induced upon prebiotic and synbiotic supplementation

608 in fecal fermentation in vitro (Vitali et al., 2012). Here it is also important to highlight the

609 difficulties at determining which bacterial group contributes to each SCFA because multiple

610 groups are often involved in the production/degradation of chemical compounds in the gut

611 (Pryde et al., 2002).

612

613 Here we show that cherry bioactive compounds (including fiber) modifies the colonic microbiota

614 and SCFA in obese diabetic mice and we hypothesized that this modification may trigger

615 changes in the gut immunity and physiology of the host. However, here we also showed that

616 cherry powder supplementation did not affect mRNA expression of several biomarkers

617 associated with gut health in spite of a change in bacterial composition and biochemistry. Only

618 ATF4 mRNA levels were different among experimental groups and downregulated in cherry-

619 supplemented mice. ATF4 can be upregulated in response to bacterial LPS as adaptive response

620 that triggers the expression of inflammatory cytokines (TNF- $\alpha$, IL-6, and IL-10), signaling 
621 pathways (NF-kB and MAPK), and the ATF4-CHOP apoptotic pathway (Rao et al., 2013).

622 Therefore, downregulation of ATF4 in supplemented group might be linked to lower levels of

623 bacteria producing LPS in the colon mucus layer, with implications for intestinal cells

624 inflammation and survival. The LPS concentrations in caecal contents might not resemble LPS in

625 lumen layer in contact with the colon mucus layers. Unfortunately, this could not be confirmed

626 due to the limitations intrinsic to the collection of specific fractions of lumen for LPS

627 determination.

628

629 In addition, the lower levels of ATF4 and VCAM-1 may also be mediated by the higher SCFAs

630 production in supplemented mice as demonstrated by Huang et al. (2017) in vitro. SCFAs

631 inhibited oxidative stress, inflammatory response, and cell adhesion molecules induced by LPS

632 and glucose through activation of their specific G protein-coupled receptors 43 (GPR43) (Huang

633 et al., 2017). Even though our experimental conditions did not compromise gut integrity and

634 barrier function as confirmed by LPS in plasma that was similar among experimental groups, our

635 study has provided insights to future studies investigating cherry intake within the context of

636 acute and chronic intestinal inflammation. The improvement in intestinal integrity by

637 polyphenolics enriched extracts, independently of alterations in gut microbiota, was

638 demonstrated over a period of only four weeks in pigs induced subclinical chronic inflammation

639 with E. coli LPS injections (Liehr et al., 2017). Because the observed changes in bacterial

640 composition and SCFAs could have been related to bioconversion of cherry compounds, it would

641 be interesting to study the effect of cherry compounds in germ-free mice, with the obvious

642 disadvantage of not representing a real-life scenario. In general, our results reveal interesting

643 research avenues for cherry intake within the context of chronic and acute intestinal 
644 inflammation using conventional and germ-free mice to determine whether the cherry-induced

645 intestinal bacteria modulation could be beneficial in ameliorating or preventing the symptoms of

646 intestinal inflammation.

647

648 This study has drawbacks that ought to be taken into account in future studies. First, cherries 649 contain fiber and a wide variety of bioactive compounds and this is important because not all 650 compounds have the same properties on health. In this regard it was not the objective of this 651 study to identify each compound individually but to assess the effect of the fruit as a whole, at

652 least in a powder form. Second, in this study we used a model of genetic obesity but diet-induced 653 obesity can also shed light into the mechanisms associated with any health effect (Hariri and 654 Thibault, 2010). One main disadvantage of using diet-induced obesity is the high number of diets 655 that can be used to promote obesity and perhaps more importantly the nutritional differences and 656 outcomes in host physiology among these diets. Also, we know now that obesity in humans is a 657 complex disorder that often involves a genetic difference in the host. Importantly, Song et al. 658 (2016) showed a beneficial effect of cherries using a diet-induced model of obesity, thus 659 suggesting that cherries can have a positive impact in different types of obesity-related disorders. 660

\section{Conclusions}

662 In summary, this study shows that cherry supplementation for 12 weeks can modify the colon 663 microbiota and the concentrations of SCFAs. Our research model did not provide strong 664 evidence to suggest that this dietary intervention can lead to changes in biomarkers of 665 inflammation, cellular stress, and gut barrier function in colonic mucosal cells and colon tissues. 666 The reason of why the change in the microbiota and SCFAs did not affect the host physiology 
667 remains to be investigated, but may be related to the obese genetic animal model used instead of

668 using high fat, high sugar to induce obesity, which is known to stimulate intestinal inflammation 669 (Rahman et al., 2016). Also, it has been shown that mice deficient for intestinal gluconeogenesis 670 do not show the same metabolic benefits on body weight and glucose control induced by SCFAs, 671 despite similar modifications in gut microbiota composition (De Vadder et al., 2014). Indeed, 672 this topic is worth exploring further, especially in a context of diabetes (Mithieux et al., 2004).

673 More research is desirable into the implications of cherry consumption as a dietary supplement in 674 diabetic and obese human patients.

675

Acknowledgments

677 We thank Mohit Sharma for technical assistance in histology analysis.

678

679

Barcenilla A, Pryde SE, Martin JC, Duncan SH, Stewart CS, Henderson C, Flint HJ. 2000.

681

682 Phylogenetic relationships of butyrate-producing bacteria from the human gut. Applied Environmental Microbiology 66(4):1654-1661.

Baron G, Altomare A, Regazzonia L, Redaelli V, Grandi S, Riva A, Morazzoni P, Mazzolari A, Carini M, Vistoli G, Aldini G. 2017. Pharmacokinetic profile of bilberry anthocyanins in rats and the role of glucose transporters: LC-MS/MS and computational studies. Journal of Pharmaceutical and Biomedical Analysis 144:112-121 DOI 10.1016/j.jpba.2017.04.042. 
688

689

690

691

692

693

694

695

696

697

698

699

700

701

702

703

704

705

706

707

708

709

Bell ET, Suchodolski JS, Isaiah A, Fleeman LM, Cook AK, Steiner JM, Mansfield CS. 2014. Faecal microbiota of cats with insulin-treated diabetes mellitus. PLoS ONE 9(10):e108729 DOI 10.1371/journal.pone.0108729.

Belzer C, de Vos WM. 2016. Microbes inside-from diversity to function: the case of Akkermansia. ISME J 6:1449-1458 DOI 10.1038/ismej.2012.6.

Bergström A, Licht TR, Wilcks A, Andersen JB, Schmidt LR, Grønlund HA, Vigsnæs LK, Michaelsen KF, Bahl MI. 2012. Introducing Gut Low-Density Array (GULDA) - a validated approach for qPCR-based intestinal microbial community analysis. FEMS Microbiology Letters 337(1):38-47 DOI 10.1111/1574-6968.12004.

Berry D, Stecher B, Schintlmeister A, Reichert J, Brugiroux S, Wild B, Wanek W, Richter A, Rauch I, Decker T, Loy A, Wagner M. 2013. Host-compound foraging by intestinal microbiota revealed by single-cell stable isotope probing. Proceedings Natural Academy of Science 110:4720-4725 DOI 10.1073/pnas.1219247110.

Berry D, Schwab C, Milinovich G, Reichert J, Ben Mahfoudh K, Decker T, Engel M, Hai B, Hainzl E, Heider S, Kenner L, Müller M, Rauch I, Strobl B, Wagner M, Schleper C, Urich T, Loy A. 2012. Phylotype-level 16S rRNA analysis reveals new bacterial indicators of health state in acute murine colitis. ISME Journal 6(11):2091-106 DOI 10.1038/ismej.2012.39.

Borton MA, Sabag-Daigle A, Wu J, Solden LM, O'Banion BS, Daly RA, Wolfe RA, Gonzalez JF, Wysocki VH, Ahmer BMM, Wrighton KC. 2017. Chemical and pathogen-induced inflammation disrupt the murine intestinal microbiome. Microbiome 5(1):47 DOI 10.1186/s40168-017-0264-8. 
710 Budak NH. 2017. Bioactive components of Prunus avium L. black gold (red cherry) and Prunus

711

712

713

714

715

716

717

718

719

720

721

722

723

724

725

726

727

728

729

730

731

732

avium L. stark gold (white cherry) juices, wines and vinegars. Journal of Food Science and Technology 54(1):62-70 DOI 10.1007/s13197-016-2434-2.

Caesar R, Tremaroli V, Kovatcheva-Datchary P, Cani PD, Bäckhed F. 2015. Crosstalk between gut microbiota and dietary lipids aggravates WAT inflammation through TLR signaling. Cell Metabolism 22:658-668 DOI 10.1016/j.cmet.2015.07.026.

Caporaso JG, Lauber CL, Walters WA, Berg-Lyons D, Huntley J, Fierer N, Owens SM, Betley J, Fraser L, Bauer M, Gormley N, Gilbert JA, Smith G, Knight R. 2012. Ultra-high-throughput microbial community analysis on the Illumina HiSeq and MiSeq platforms. ISME Journal 6:1621-1624. DOI 10.1038/ismej.2012.8.

Chen T, Long W, Zhang C, Liu S, Zhao L, Hamaker BR. 2017. Fiber-utilizing capacity varies in Prevotella- versus Bacteroides-dominated gut microbiota. Scientific Reports 7(1):2594 DOI 10.1038/s41598-017-02995-4.

Cho KS, Lim YR, Lee K, Lee J, Lee JH, Lee IS. 2017. Terpenes from forests and human health. Toxicological Research 33(2):97-106 DOI 10.5487/TR.2017.33.2.097.

Cires MJ, Wong X, Carrasco-Pozo C, Gotteland M. 2017. The gastrointestinal tract as a key target organ for the health-promoting effects of dietary proanthocyanidins. Frontiers in Nutrition 3:57 DOI 10.3389/fnut.2016.00057.

Condezo-Hoyos L, Mohanty IP, Noratto GD. 2014. Assessing non-digestible compounds in apple cultivars and their potential as modulators of obese faecal microbiota in vitro. Food Chemistry 161:208-215 DOI 10.1016/j.foodchem.2014.03.122.

Conlon MA, Bird AR. 2014. The impact of diet and lifestyle on gut microbiota and human health. Nutrients 7(1):17-44 DOI 10.3390/nu7010017. 
733

734

735

736

737

738

739

740

741

742

743

744

Dahan S, Segal Y, Shoenfeld Y. 2017. Dietary factors in rheumatic autoimmune diseases: a recipe for therapy? Nature Reviews Rheumatology DOI 10.1038/nrrheum.2017.42.

Dao MC, Everard A, Aron-Wisnewsky J, Sokolovska N, Prifti E, Verger EO, Kayser BD, Levenez F, Chilloux J, Hoyles L, MICRO-Obes Consortium, Dumas ME, Rizkalla SW, Doré J, Cani PD, Clément K. 2016. Akkermansia muciniphila and improved metabolic health during a dietary intervention in obesity: relationship with gut microbiome richness and ecology. Gut 65(3):426-436 DOI 10.1136/gutjnl-2014-308778.

De Vadder F, Kovatcheva-Datchary P, Goncalves D, Vinera J, Zitoun C, Duchampt A, Bäckhed F, Mithieux G. 2014. Microbiota-generated metabolites promote metabolic benefits via gut-brain neural circuits. Cell 156:84-96 DOI 10.1016/j.cell.2013.12.016.

Derrien M, Collado MC, Ben-Amor K, Salminen S, de Vos WM. 2008. The mucin degrader Akkermansia muciniphila is an abundant resident of the human intestinal tract. Applied Environmental Microbiology 74:1646-1648 DOI 10.1128/AEM.01226-07.

Derrien M, van Baarlen P, Hooiveld G, Norin E, Muller M, de Vos WM. 2011. Modulation of mucosal immune response, tolerance and proliferation in mice colonized by the mucindegrader Akkermansia muciniphila. Frontiers in Microbiology 2:166 DOI 10.3389/fmicb.2011.00166.

DeSantis TZ, Hugenholtz P, Larsen N, Rojas M, Brodie EL, Keller K, Huber T, Dalevi D, Hu P, Andersen GL. 2006. Greengenes, a chimera-checked 16S rRNA gene database and workbench compatible with ARB. Applied Environmental Microbiology 72(7):50695072 DOI 10.1128/AEM.03006-05. 
754 de Vos WM. 2017. Microbe profile: Akkermansia muciniphila: a conserved intestinal symbiont

755 that acts as the gatekeeper of our mucosa. Microbiology 163:646-648 DOI

756 10.1099/mic.0.000444.

757

758

759

760

761

762

763

764

765

766

767

768

769

770

771

772

773

774

775

Everard A, Belzer C, Geurts L, Ouwerkerk JP, Druart C, Bindels LB, Guiot Y, Derrien M, Muccioli GG, Delzenne NM, de Vos WM, Cani PD. 2013. Cross-talk between Akkermansia muciniphila and intestinal epithelium controls diet-induced obesity. Proceedings of Natural Academy Science USA 110:9066-71 DOI 10.1073/pnas.1219451110.

Everard A, Lazarevic V, Derrien M, Girard M, Muccioli GM, Neyrinck AM, Possemiers S, Van Holle A, Francois P, de Vos WM, Delzenne NM, Schrenzel J, Cani PD. 2011. Responses of gut microbiota and glucose and lipid metabolism to prebiotics in genetic obese and diet-induced leptin-resistant mice. Diabetes 60:2775-2786 DOI 10.2337/db110227.

Faria A, Fernandes I, Norberto S, Mateus N, Conceição C. 2014. Interplay between anthocyanins and gut microbiota. Journal of Agricultural and Food Chemistry 62(29):6898-6902 DOI 10.1021/jf501808a.

Ganesh BP, Klopfleisch R, Loh G, Blaut M. 2013. Commensal Akkermansia muciniphila exacerbates gut inflammation in Salmonella typhimurium-infected gnotobiotic mice. PLoS One 8(9):e74963 DOI: 10.1371/journal.pone.0074963.

Garcia-Mazcorro JF, Mills D, Noratto G. 2016a. Molecular exploration of fecal microbiome in quinoa-supplemented obese mice. FEMS Microbiology Ecology 92(7): fiw089 DOI 10.1093/femsec/fiw089. 
776

777

778

779

780

781

782

783

784

785

786

787

788

789

790

791

792

793

794

795

796

797

Garcia-Mazcorro JF, Ivanov I, Mills DA, Noratto G. 2016b. Influence of whole-wheat consumption on fecal microbial ecology of obese diabetic mice. PeerJ 2016 4:e1702 DOI $10.7717 /$ peerj. 1702 .

Garcia-Mazcorro JF, Mills DA, Murphy K, Noratto G. 2017. Effect of barley supplementation on the fecal microbiota, caecal biochemistry, and key biomarkers of obesity and inflammation in obese $\mathrm{db} / \mathrm{db}$ mice. European Journal of Nutrition DOI 10.1007/s00394-017-1523-y (Epub ahead of print).

Håkansson A, Tormo-Badia N, Baridi A, Xu J, Molin G, Hagslätt ML, Karlsson C, Jeppsson B, Cilio CM, Ahrné S. 2015. Immunological alteration and changes of gut microbiota after dextran sulfate sodium (DSS) administration in mice. Clinical and Experimental Medicine 15(1):107-20 DOI 10.1007/s10238-013-0270-5.

Hammer Ø, Harper DAT, Ryan PD. 2001. PAST: paleontological statistics software package for education and data analysis. Paleontologia Electronica 4:1-9.

Hariri N, Thibault L. 2010. High-fat diet-induced obesity in animal models. Nutrition Research Reviews 23:270-299 DOI 10.1017/S0954422410000168.

He Y, Caporaso JG, Jiang XT, Sheng HF, Huse SM, Rideout JR, Edgar RC, Kopylova E, Walters WA, Knight R, Zhou HW. 2015. Stability of operational taxonomic units: an important but neglected property for analyzing microbial diversity. Microbiome 3:20 DOI 10.1186/s40168-015-0081-X.

Henning SM, Summanen PH, Lee RP, Yang J, Finegold SM, Heber D, Li Z. 2017. Pomegranate ellagitannins stimulate the growth of Akkermansia muciniphila in vivo. Anaerobe 43:56-60. DOI 10.1016/j.anaerobe.2016.12.003. 
798

799

800

801

802

803

804

805

806

807

808

809

810

811

812

813

814

815

816

817

818

819

Huang W, Guo HL, Deng X, Zhu TT, Xiong JF, Xu YH, Xu Y. 2017. Short-chain fatty acids inhibit oxidative stress and inflammation in mesangial cells induced by high glucose and lipopolysaccharide. Experimental and Clinical Endocrinology \& Diabetes 125(2):98-105 DOI 10.1055/s-0042-121493.

Jayaprakasam B, Olson LK, Schutzki RE, Tai MH, Nair MG. 2006. Amelioration of obesity and glucose intolerance in high-fat-fed C57BL/6 mice by anthocyanins and ursolic acid in Cornelian cherry (Cornus mas). Journal of Agricultural and Food Chemistry 54(1):243-248 DOI 10.1021/jf0520342.

Jeyakumar SM, Vajreswari A, Giridharan NV. 2006. Chronic dietary vitamin A supplementation regulates obesity in an obese mutant WNIN/Ob rat model. Obesity 14(1):52-59. DOI 10.1038/oby.2006.7

Johansson ME, Phillipson M, Petersson J, Velcich A, Holm L, Hansson GC. 2008. The inner of the two Muc2 mucin-dependent mucus layers in colon is devoid of bacteria. Proc Natl Acad Sci USA 105(39):15064-15069 DOI 10.1073/pnas.0803124105.

Kang CS, Ban M, Choi EJ, Moon HG, Jeon JS, Kim DK, Park SK, Jeon SG, Roh TY, Myung SJ, Gho YS, Kim JG, Kim YK. 2013. Extracellular vesicles derived from gut microbiota, especially Akkermansia muciniphila, protect the progression of dextran sulfate sodium-induced colitis. PLoS One 8(10): 76520 DOI 10.1371/journal.pone.0076520.

Karlsson FH, Ussery DW, Nielsen J, Nookaew I. 2010. A closer look at Bacteroides: phylogenetic relationship and genomic implications of a life in the human gut. Microbiology Ecology 61(3):473-485 DOI 10.1007/s00248-010-9796-1. 
820 Khan MA, Ahmad R, Srivastava AN. 2016. Effect of methyl butyrate aroma on the survival

821

822

823

824

825

826

827

828

829

830

831

832

833

834

835

836

837

838

839

840

841

842

and viability of human breast cancer cells in vitro. Journal of the Egyptian National Cancer Institute 28(2):81-88 DOI 10.1016/j.jnci.2016.02.005.

Langille MGI, Zanevekd J, Caporaso JG, McDonald D, Knights D, Reyes JA, Clemente JC, Burkepile DE, Vega Thurber RL, Knight R, Beiko RG, Huttenhower C. 2013. Predictive functional profiling of microbial communities using 16S rRNA marker gene sequences. Nature Biotechnology 31:814-823 DOI 10.1038/nbt.2676

Liehr M, Mereu A, Pastor JJ, Quintela JC, Staats S, Rimbach G, Ipharraguerre IR. 2017. Olive oil bioactives protect pigs against experimentally-induced chronic inflammation independently of alterations in gut microbiota. PLoS ONE 12(3):e0174239 DOI 10.1371/journal.pone.0174239.

Lozupone C, Knight R. 2005. UniFrac: a new phylogenetic method for comparing microbial communities. Applied Environmental Microbiology 71(12):8228-8235 DOI 10.1128/AEM.71.12.8228-8235.2005.

Lozupone CA, Hamady M, Kelley ST, Knight R. 2007. Quantitative and qualitative $\beta$ diversity measures lead to different insights into factors that structure microbial communities. Applied Environmental Microbiology 73(5):1576-1585.

Luo J, Zhang P, Li S, Shah NP. 2016. Antioxidant, antibacterial, and antiproliferative activities of free and bound phenolics from peel and flesh of fuji apple. Journal of Food Science 81(7):M1735-1742 DOI 10.1111/1750-3841.13353.

Martini S, Conte A, Tagliazucchi D. 2017. Phenolic compounds profile and antioxidant properties of six sweet cherry (Prunus avium) cultivars. Food Research International 97:15-26 DOI 10.1016/j.foodres.2017.03.030. 
843 McCune LM, Kubota C, Stendell-Hollis NR, Thomson CA. 2011. Cherries and health: a

844

845

846

847

848

849

850

851

852

853

854

855

856

857

858

859

860

861

862

863

864

865

review. Critical Reviews in Food Science and Nutrition 51(1):1-12 DOI

10.1080/10408390903001719.

Mikulic-Petkovsek M, Stampar F, Veberic R, Sircelj H. 2016. Wild prunus fruit species as a rich source of bioactive compounds. Journal of Food Science 81(8):C1928-1937 DOI 10.1111/1750-3841.13398.

Mithieux G, Bady I, Gautier A, Croset M, Rajas F, Zitoun C. 2004. Induction of control genes in intestinal gluconeogenesis is sequential during fasting and maximal in diabetes. American Journal of Physiology, Endocrinology and Metabolism. 286(3):E370-375 DOI: 10.1152/ajpendo.00299.2003.

Modi SR, Collins JJ, Relman DA. 2014. Antibiotics and the gut microbiota. The Journal of Clinical Investigation 124(10):4212-4218 DOI 10.1172/JCI72333.

\section{Negroni A, Prete E, Vitali R, Cesi V, Aloi M, Civitelli F, Cucchiara S, Stronati L. 2014.} Endoplasmic reticulum stress and unfolded protein response are involved in paediatric inflammatory bowel disease. Digestive Liver Disease 46(9):788-794 DOI 10.1016/j.dld.2014.05.013.

Noratto G, Chew BP, Ivanov I. 2016. Red raspberry decreases heart biomarkers of cardiac remodeling associated with oxidative and inflammatory stress in obese diabetic $\mathrm{db} / \mathrm{db}$ mice. Food \& Function 7(12):4944-4955 DOI 10.1039/c6fo01330a.

\section{Noratto G, Garcia-Mazcorro JF, Markel M, Martino HS, Minamoto Y, Steiner JM, Byrne} D, Suchodolski JS, Talcott S. 2014. Carbohydrate-free peach (Prunus persica) and plum (Prunus salicina) juice affects fecal microbial ecology in an obese animal model. PLoS ONE 9(7):e101723 DOI 10.1371/journal.pone.0101723. 
866

867

868

869

870

871

872

873

874

875

876

877

878

879

880

881

882

883

884

885

886

887

888

Ormerod KL, Wood DL, Lachner N, Gellatly SL, Daly JN, Parsons JD, Dal'Molin CG, Palfreyman RW, Nielsen LK, Cooper MA, Morrison M, Hansbro PM, Hugenholtz P. 2016. Genomic characterization of the uncultured Bacteroidales family S24-7 inhabiting the guts of homeothermic animals. Microbiome 4:36 DOI 10.1186/s40168016-0181-2.

Ottman N, Reunanen J, Meijerink M, Pietilä TE, Kainulainen V, Klievink J, Huuskonen L, Aalvink S, Skurnik M, Boeren S, Satokari R, Mercenier A, Palva A, Smidt H, de Vos WM, Belzer C. 2017. Pili-like proteins of Akkermansia muciniphila modulate host immune responses and gut barrier function. PLoS ONE 12(3):e0173004 DOI 10.1371/journal.pone.0173004.

Panche AN, Diwan AD, Chandra SR. 2016. Flavonoids: an overview. Journal of Nutritional Science 5:e47 DOI 10.1017/jns.2016.41.

Palmer SC, Maggo JK, Campbell KL, Craig JC, Johnson DW, Sutanto B, Ruospo M, Tong A, Strippoli GF. 2017. Dietary interventions for adults with chronic kidney disease. The Cochrane Database of Systematic Reviews 4:CD011998 DOI 10.1002/14651858.CD011998.pub2.

Parks DH, Beiko RG. 2010. Identifying biologically relevant differences between metagenomic communities. Bioinformatics 26:715-721 DOI 10.1093/bioinformatics/btq041.

Pelaseyed T, Bergström JH, Gustafsson JK, Ermund A, Birchenough GMH, Schütte A, van der Post S, Svensson F, Rodriguez-Piñeiro AM, Nyström EEL, Wising C, Johansson MEV, Hansson GC. 2014. The mucus and mucins of the goblet cells and enterocytes provide the first defense line of the gastrointestinal tract and interact with the immune system. Immnological Reviews 260(1):8-20 DOI 10.1111/imr.12182. 
889 Pérez-Jiménez J, Neveu V, Vos F, Scalbert A. 2010. Identification of the 100 richest dietary

890 sources of polyphenols: an application of the Phenol-Explorer database. European

891 Journal of Clinical Nutrition 64(Suppl 3):S112-120 DOI 10.1038/ejcn.2010.221.

892

893

894

895

896

897

898

899

900

901

902

903

904

905

906

907

908

909
Png CW, Linden SK, Gilshenan KS, Zoetendal EG, McSweeney CS, McGuckin MA, Florin TH. 2010. Mucolytic bacteria with increased prevalence in IBD mucosa augment in vitro utilization of mucin by other bacteria. American Journal of Gastroenterology 115:24202428.

Pryde SE, Duncan SH, Hold GL, Stewart CS, Flint HJ. 2002. The microbiology of butyrate formation in the human colon. FEMS Microbiology Letters 217:133-139.

Rahman K, Desai C, Iyer SS, Thorn NE, Kumar P, Liu Y, Smith T, Neish AS, Li H, Tan S, Wu P, Liu X, Yu Y, Farris AB, Nusrat A, Parkos CA, Anania FA. 2016. Loss of junctional adhesion molecule A promotes severe steatohepatitis in mice on a diet high in saturated fat, fructose, and cholesterol. Gastroenterology 151(4):733-746 DOI 10.1053/j.gastro.2016.06.022.

Ramos MG, Bambirra EA, Cara DC, Vieira EC, Alvarez-Leite JI. 1997. Oral administration of short-chain fatty acids reduces the intestinal mucositis caused by treatment with Ara-C in mice fed commercial or elemental diets. Nutrition and Cancer 28(2):212-217.

Rao J, Qin J, Qian X, Lu L, Wang P, Wu Z, Zhai Y, Zhang F, Li G, Wang X. 2013. Lipopolysaccharide preconditioning protects hepatocytes from ischemia/reperfusion injury (IRI) through inhibiting ATF4-CHOP pathway in mice. PLoS One 8(6): e65568 DOI 10.1371/journal.pone.0065568. 
910 Redondo D, Arias E, Oria R, Venturini ME. 2017. Thinned stone fruits are a source of

911

912

913

914

915

916

917

918

919

920

921

922

923

924

925

926

927

928

929

930

931

polyphenols and antioxidant compounds. Journal of the Science of Food and Agriculture 97(3):902-910 DOI 10.1002/jsfa.7813.

Rideout JR, He Y, Navas-Molina JA, Walters WA, Ursell LK, Gibbons SM, Chase J, McDonald D, Gonzalez A, Robbins-Pianka A, Clemente JC, Gilbert JA, Huse SM, Zhou HW, Knight R, Caporaso JG. 2014. Subsampled open-reference clustering creates consistent, comprehensive OTU definitions and scales to billions of sequences. PeerJ 2:e545 DOI 10.7717/peerj.545.

Rios-Covian DN, Salazar N, Gueimonde M, de Los Reyes-Gavilan CG. 2017. Shaping the metabolism of intestinal Bacteroides population through diet to improve human health. Frontiers in Microbiology 8:376 DOI 10.3389/fmicb.2017.00376.

Rowland I, Gibson G, Heinken A, Scott K, Swann J, Thiele I, Tuohy K. 2017. Gut microbiota functions: metabolism of nutrients and other food components. European Journal of Nutrition DOI 10.1007/s00394-017-1445-8.

Schmittgen TD, Livak KJ (2008) Analyzing real-time PCR data by the comparative C(T) method. Nature Protocols 3(6):1101-1108.

Sheflin AM, Melby CL, Carbonero F, Weir TL. 2016. Linking dietary patterns with gut microbial composition and function. Gut Microbes 8(2):113-129 DOI 10.1080/19490976.2016.1270809.

Song H, Wu T, Xu D, Chu Q, Lin D, Zheng X. 2016. Dietary sweet cherry anthocyanins attenuates diet-induced hepatic steatosis by improving hepatic lipid metabolism in mice. Nutrition 32(7-8):827-833 DOI 10.1016/j.nut.2016.01.007. 
932 Sonnenburg JL, Xu J, Leip DD, Chen CH, Westover BP, Weatherford J, Buhler JD,

933 Gordon JI. 2005. Glycan foraging in vivo by an intestine-adapted bacterial symbiont.

934 Science 307(5717):1955-1959.

935 Stalmach A, Mullen W, Steiling H, Williamson G, Lean ME, Crozier A. 2010. Absorption, 936 metabolism, and excretion of green tea flavan-3-ols in humans with an ileostomy.

937 Molecular Nutrition and Food Research 54(3):323-334 DOI 10.1002/mnfr.200900194.

Suzuki T, Yoshida S, Hara H. 2008. Physiological concentrations of short-chain fatty acids immediately suppress colonic epithelial permeability. The British Journal of Nutrition 100(2):297-305 DOI 10.1017/S0007114508888733.

Swidsinski A, Dorffel Y, Loening-Baucke V, Theissig F, Ruckert JC, Ismail M, Rau WA, appendicitis is characterised by local invasion with Fusobacterium nucleatum/necrophorum. Gut 60(1):34-40 DOI 10.1136/gut.2009.191320.

Swidsinski A, Loening-Baucke V, Vaneechoutte M, Doerffel Y. 2008. Active Crohn's disease and ulcerative colitis can be specifically diagnosed and monitored based on the biostructure of the fecal flora. Inflammatory Bowel Diseases 14(2):147-161 DOI 10.1002/ibd.20330.

Tan J, McKenzie C, Potamitis M, Thorburn AN, Mackay CR, Macia L. 2014. The role of 950 short-chain fatty acids in health and disease. Advances in immunology 121:91-119 DOI 10.1016/B978-0-12-800100-4.00003-9.

Totsuka N, Kim YG, Kanemaru K, Niizuma K, Umemoto E, Nagai K, Tahara-Hanaoka S, receptor 4 and MAIR-II/CLM-4/LMIR2 immunoreceptor regulate VLA-4-mediated 

10.1038/ncomms5710.

957

958

959

960

961

962

963

964

965

966

967

968

969

970

971

972

973

974

975

976

977

Van den Abbeele P, Gerard P, Rabot S, Bruneau A, El Aidy S, Derrien M, Kleerebezem M, Zoetendal EG, Smidt H, Verstraete W, Van de Wiele T, Possemiers S. 2011. Arabinoxylans and inulin differentially modulate the mucosal and luminal gut microbiota and mucin-degradation in humanized rats. Environmental Microbiology 13:2667-2680 DOI 10.1111/j.1462-2920.2011.02533.x.

van Passel MWJ, Kant R, Zoetendal EG, Plugge CM, Derrien M, Malfatti SA, Chain PSG, Woyke T, Palva A, de Vos WM, Smidt H. 2011. The genome of Akkermansia muciniphila, a dedicated intestinal mucin degrader, and its use in exploring intestinal metagenomes. PLoS ONE 6(3):e16876 DOI 10.1371/journal.pone.0016876.

Velly H, Britton RA, Preidis GA. 2016. Mechanisms of cross-talk between the diet, the intestinal microbiome, and the undernourished host. Gut Microbes 5:1-15 DOI 10.1080/19490976.2016.1267888.

Via MA, Mechanick JI. 2016. Nutrition in type 2 diabetes and the metabolic syndrome. The Medical Clinics of North America 100(6):1285-1302 DOI 10.1016/j.mcna.2016.06.009.

Vitali B, Ndagijimana M, Maccaferri S, Biagi E, Guerzoni ME, Brigidi P. 2012. An in vitro evaluation of the effect of probiotics and prebiotics on the metabolic profile of human microbiota. Anaerobe 18(4):386-391 DOI 10.1016/j.anaerobe.2012.04.014.

Wang M, Jiang N, Wang Y, Jiang D, Feng X. 2017. Characterization of phenolic compounds from early and late ripening sweet cherries and their antioxidant and antifungal activities. Journal of Agricultural and Food Chemistry 65(26): 5413-5420 DOI 10.1021/acs.jafc. 7 b01409. 
978 Wu GD, Chen J, Hoffmann C, Bittinger K, Chen YY, Keilbaugh SA, Bewtra M, Knights D,

979 Walters WA, Knight R, Sinha R, Gilroy E, Gupta K, Baldassano R, Nessel L, Li H,

980

981

982

983

984

985

986

987

988

989

990

991

992

993

994

995

996

997

Bushman FD, Lewis JD. 2011. Linking long-term dietary patterns with gut microbial enterotypes. Science 334(6052):105-108 DOI 10.1126/science.1208344.

Wu T, Tang Q, Yu Z, Gao Z, Hu H, Chen W, Zheng X, Yu T. 2014. Inhibitory effects of sweet cherry anthocyanins on the obesity development in C57BL/6 mice. International Journal of Food Sciences and Nutrition 65(3):351-359 DOI 10.3109/09637486.2013.854749.

Wu T, Yin J, Zhang G, Long H, Zheng X. 2016. Mulberry and cherry anthocyanin consumption prevents oxidative stress and inflammation in diet-induced obese mice. Molecular Nutrition \& Food Research 60(3):687-694 DOI 10.1002/mnfr.201500734.

Yamada Y, Kuzuyama T, Komatsu M, Shin-Ya K, Omura S, Cane DE, Ikeda H. 2015. Terpene synthases are widely distributed in bacteria. Proceedings of the National Academy of Sciences of the USA 112(3):857-862 DOI 10.1073/pnas.1422108112.

Yang YW, Chen MK, Yang BY, Huang XJ, Zhang XR, He LQ, Zhang J, Hua ZC. 2015. Use of 16S rRNA gene-targeted group-specific primers for real-time PCR analysis of predominant bacteria in mouse feces. Applied Environmental Microbiology 81(19):67496756 DOI 10.1128/AEM.70.12.7220-7228.2004

Zhang C, Yang H, Yang F, Ma Y. 2009. Current progress on butyric acid production by fermentation. Current Microbiology 59(6):656-663 DOI 10.1007/s00284-009-9491-y. 


\section{Figure 1}

Bar plots showing relative abundance (percentages, $x$ axis) of the most abundant bacterial taxa at the family level.

$A=$ Lean, $B=$ Obese, $C=$ Cherry supplemented group. Please note the noticeable difference in the abundance of the S24-7 group, Bacteroidaceae, Lactobacillaceae, Akkermansia (family Verrucomicrobiaceae), and Enterobacteriaceae (highlighted for better visualization).

Statistical significant differences were found for these groups using either $16 \mathrm{~S}$ sequencing, qPCR analyses, or both (see main text for details). 


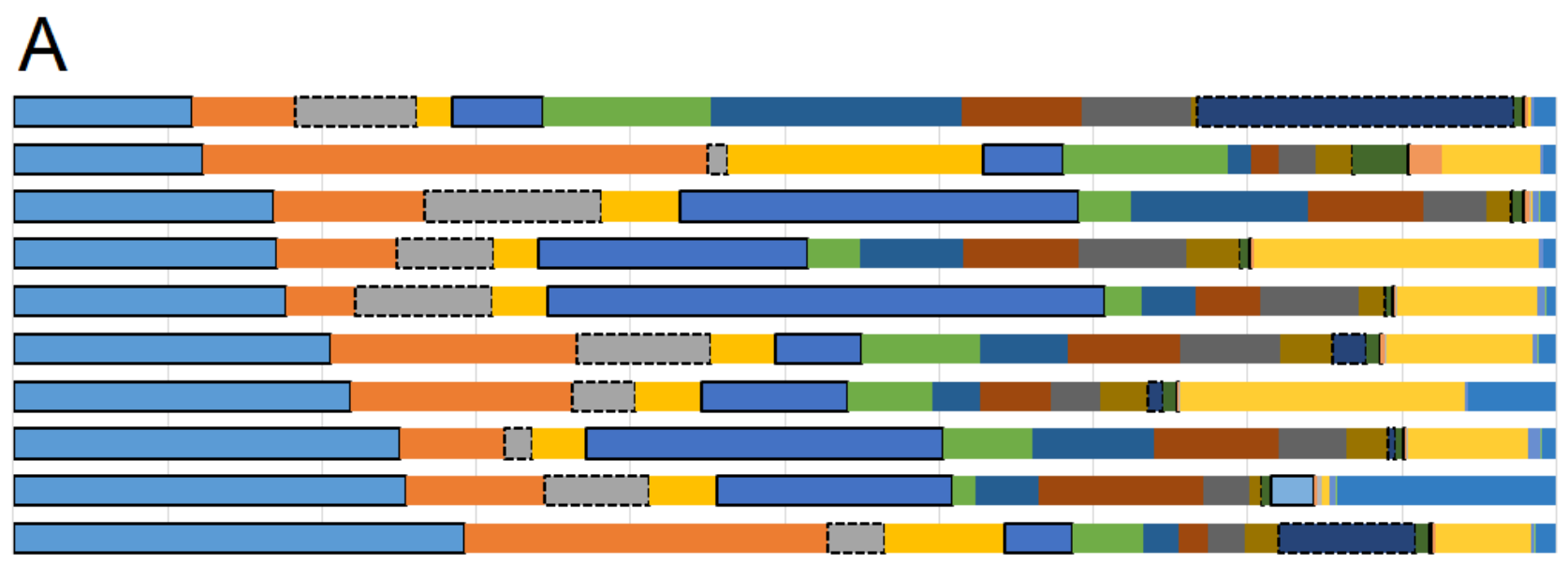

\section{B}

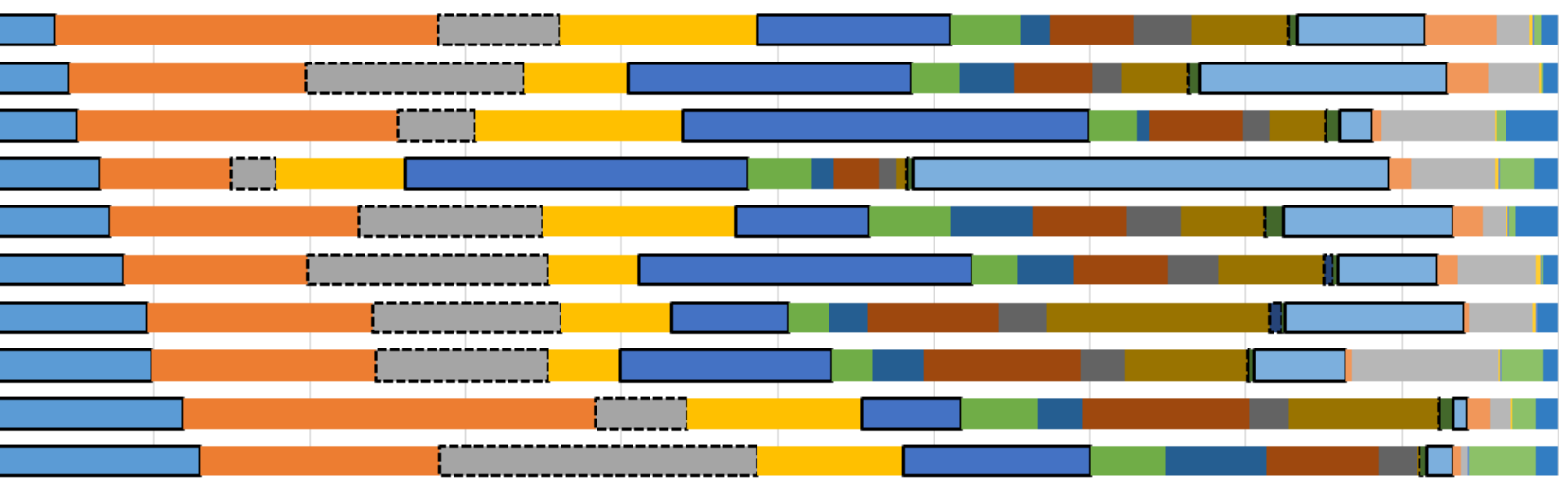

C

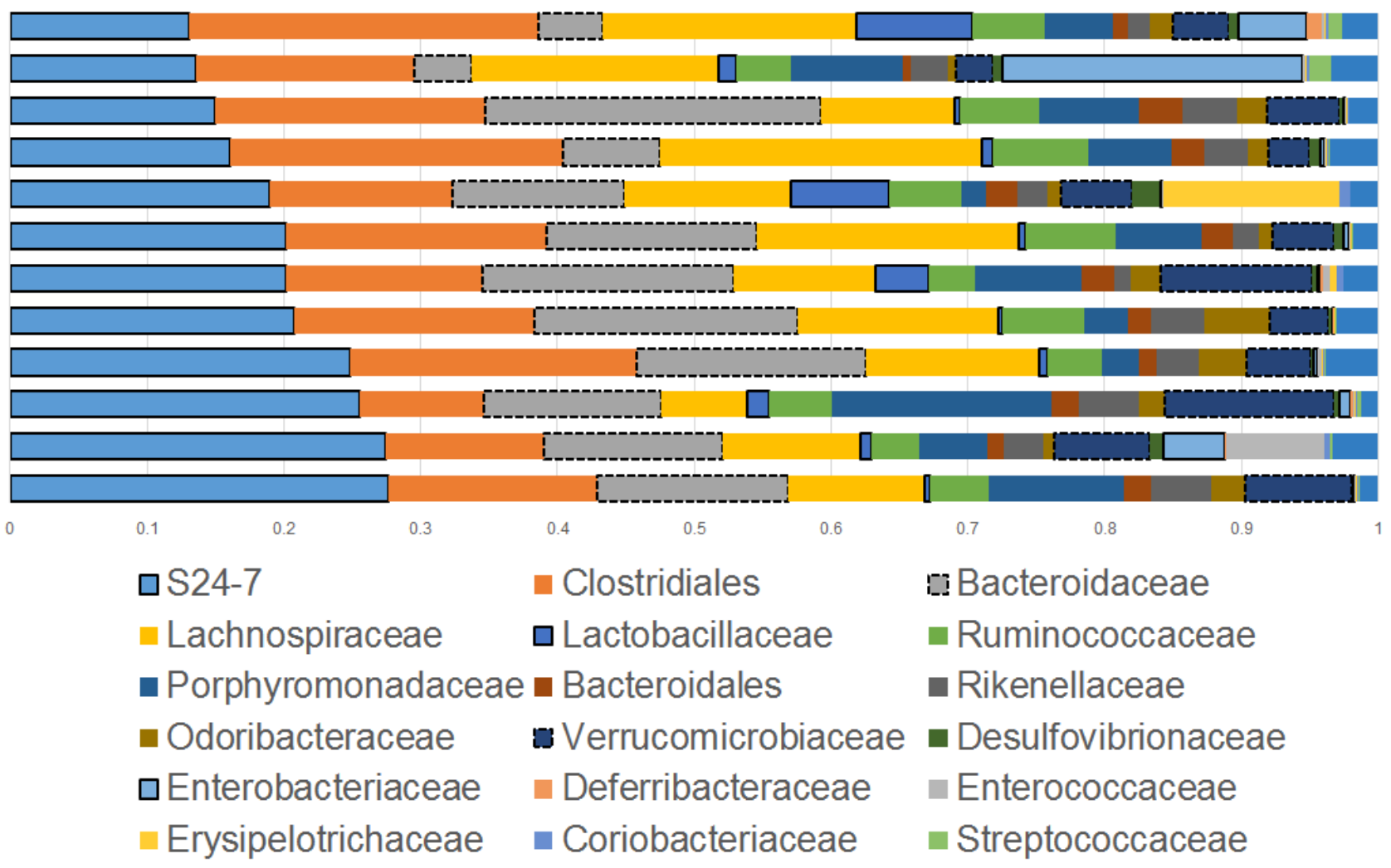


Figure 2

Alpha rarefaction plot for all treatment groups.

A flat line would indicate that the analysis of more sequences would not be able to detect more species (OTUs at $97 \%$ similarity).

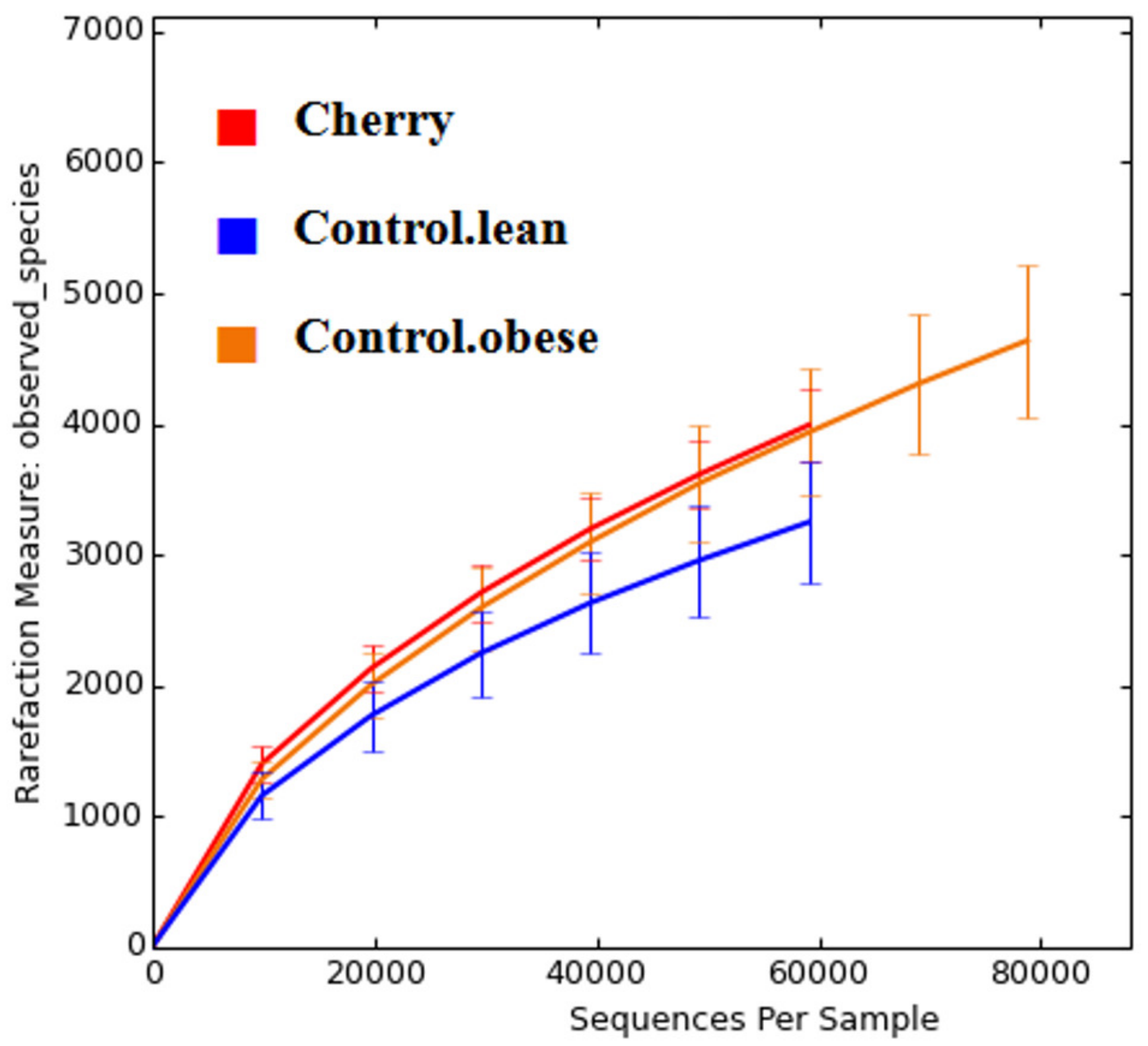




\section{Figure 3}

PCoA plots of weighted (A) and unweighted (B) UniFrac distance matrices.

Please note that the clustering of samples according to treatment is stronger (i.e. show less overlap) in the plot using the unweighted UniFrac distance matrix ( $p=0.001, R=0.844$, ANOSIM test) compared to the plot using the weighted UniFrac distance matrix ( $p=0.001$, $\mathrm{R}=0.716$, ANOSIM test).

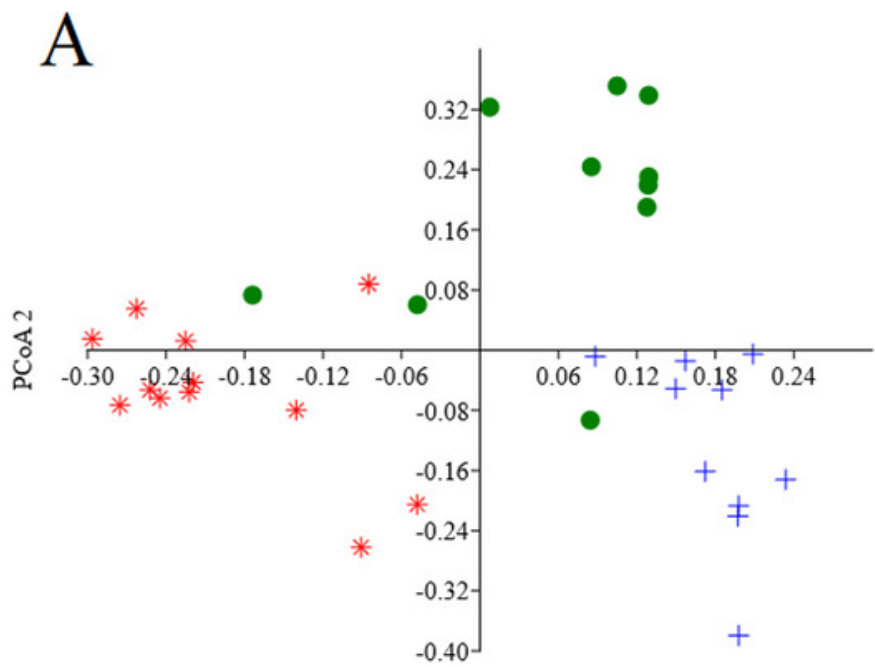

PCoA 1

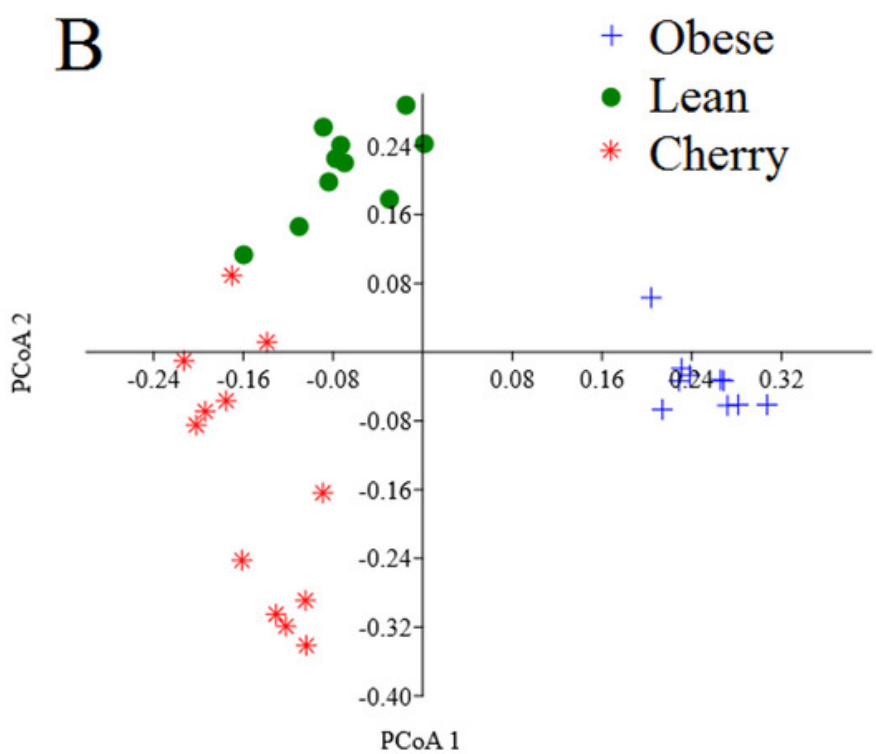




\section{Figure 4}

Boxplots showing qPCR results for selected bacterial groups in colon contents (or colon mucosa) that showed or almost reached statistical significance difference.

$P$ values come from the Kruskal-Wallis test. $A=A$ kkermansia, $B=$ Bacteroides fragilis, $C=$ Bacteroides vulgatus, $\mathrm{D}=$ Bacteroides/Prevotella, $\mathrm{E}=$ Bacteroidetes, $\mathrm{E}^{*}=$ Bacteroidetes (colonic mucosa), $\mathrm{F}=$ Betaproteobacteria, $\mathrm{F} *=$ Betaproteobacteria (colonic mucosa), $\mathrm{G}=$ Clostridium butyricum, $\mathrm{G}^{*}=$ Clostridium butyricum (colonic mucosa), $\mathrm{H}=$ Clostridium cluster IV, I= E. coli J=Enterobacteriaceae, J*= Enterobacteriaceae (colonic mucosa), $\mathrm{K}=$ Enterococcus, $\mathrm{L}=$ Faecalibacterium, $\mathrm{M}=$ Lactobacillus plantarum, $\mathrm{N}=$ Lactobacillus, $\mathrm{O}=$ Ruminococcaceae, $\mathrm{P}=$ Tenericutes. $\mathrm{qPCR}$ data is expressed as log amount of amplified DNA (in picograms) per $10 \mathrm{ng}$ of total isolated DNA. 


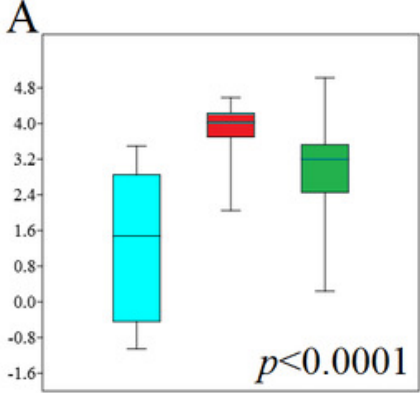

Obese Cherry Lean

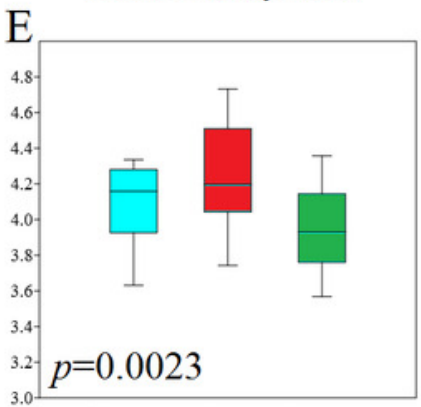

Obese Cherry Lean

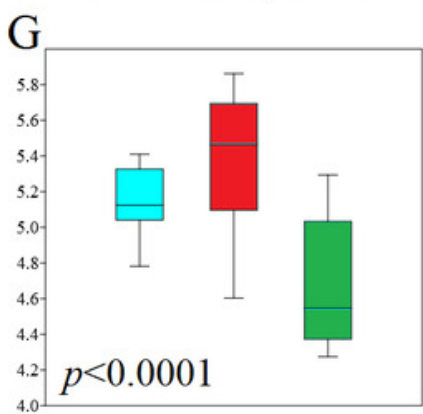

Obese Cherry Lean

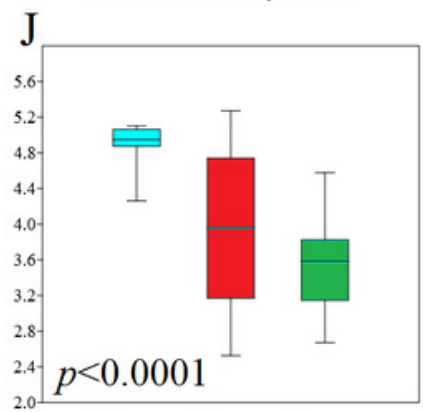

Obese Cherry Lean

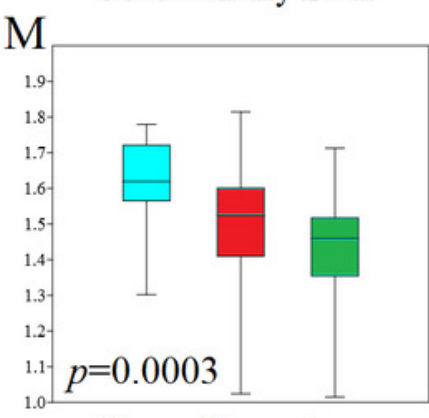

Obese Cherry Lean

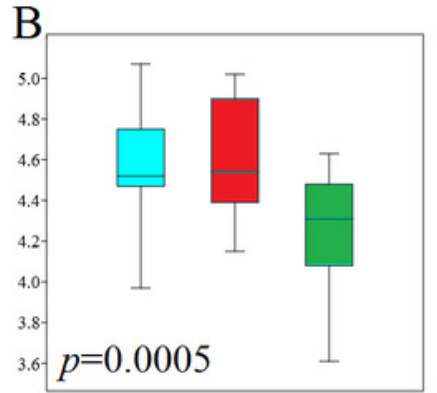

Obese Cherry Lean

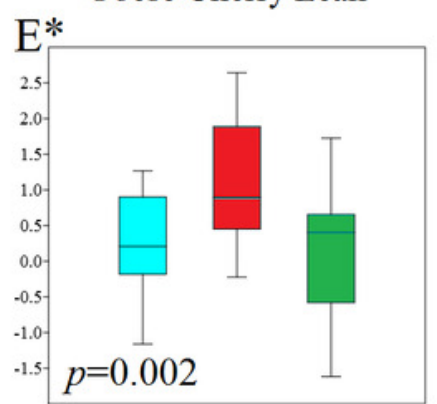

Obese Cherry Lean

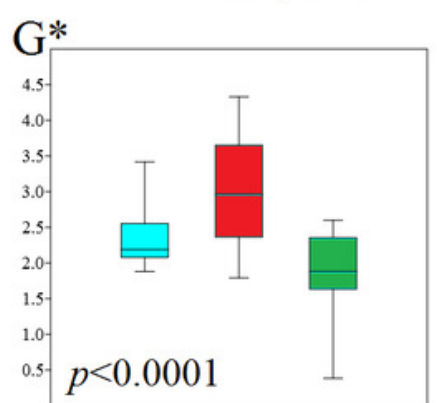

Obese Cherry Lean

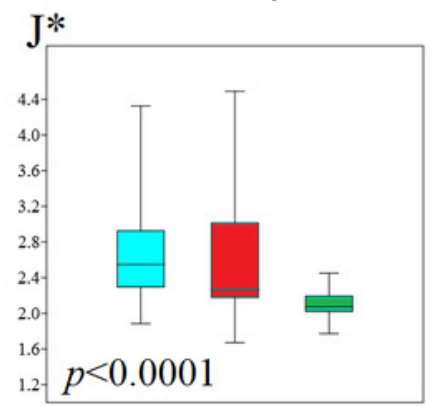

Obese Cherry Lean

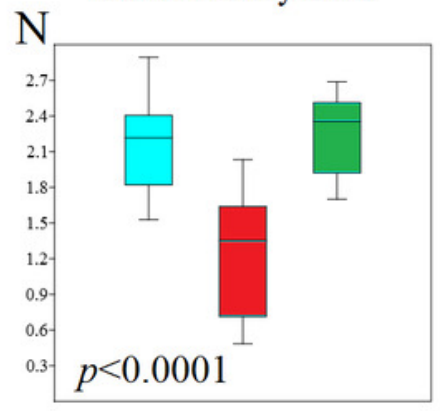

Obese Cherry Lean

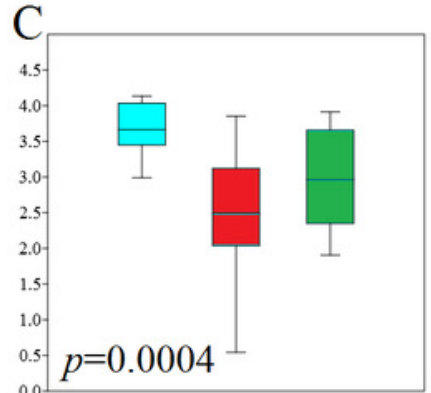

Obese Cherry Lean

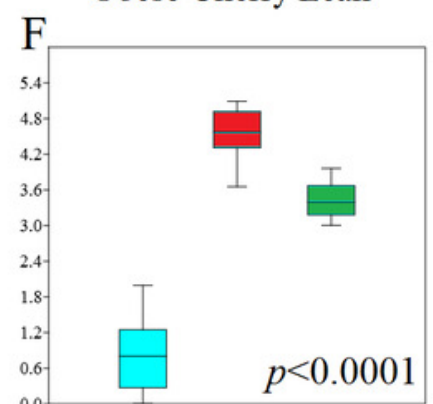

Obese Cherry Lean

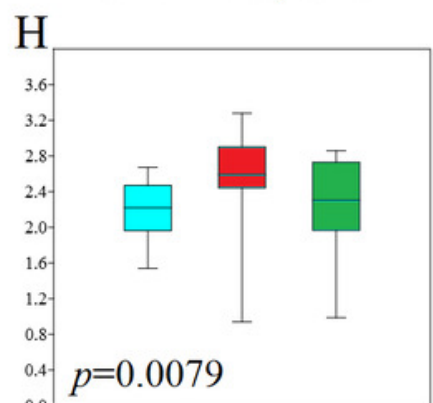

Obese Cherry Lean

K

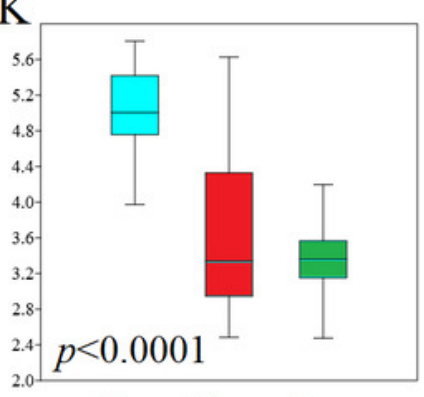

Obese Cherry Lean

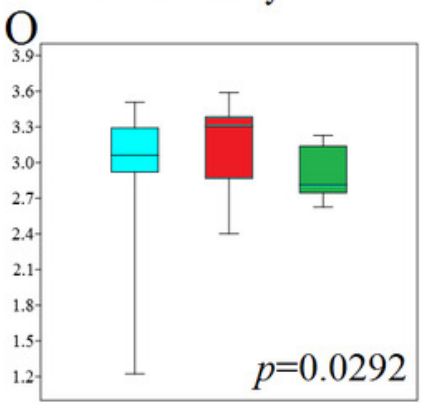

Obese Cherry Lean

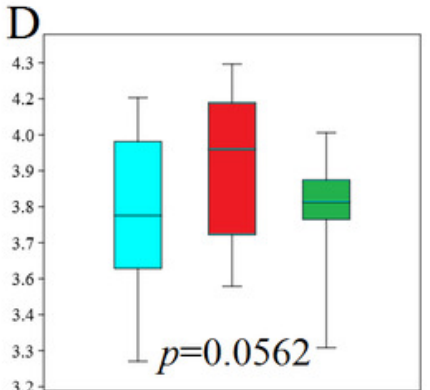

Obese Cherry Lean

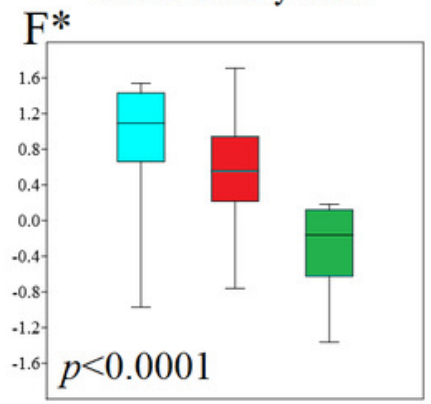

Obese Cherry Lean

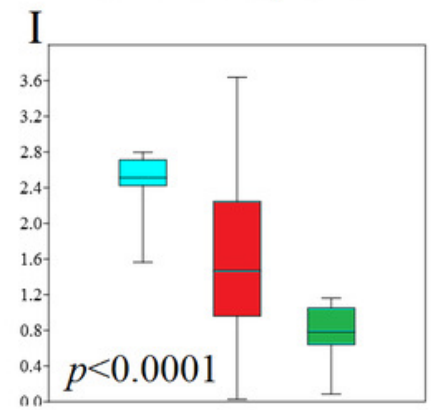

Obese Cherry Lean

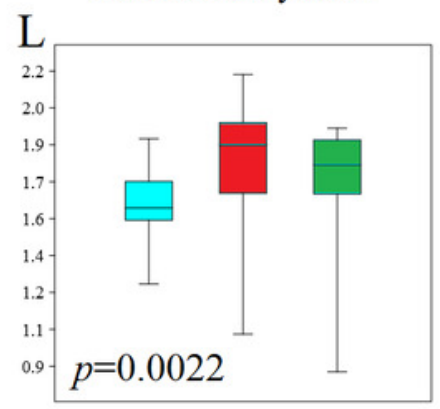

Obese Cherry Lean

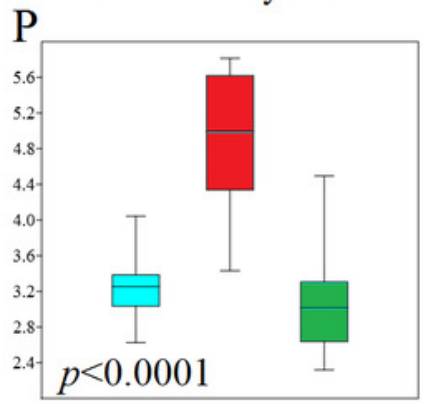

Obese Cherry Lean 


\section{Table $\mathbf{1}$ (on next page)}

Diets utilized in this study without cherry supplementation (control) and with 10\% cherry supplementation.

${ }^{1}$ AIN-93G-MX supplied by Dyets Inc. (Bethlehem, PA), containing ( $/ \mathrm{gg}$ ): Calcium Carbonate (357), Potassium Phosphate, monobasic (196), Potassium Citrate .H20 (70.78), Sodium Chloride (74), Potassium Sulfate (46.6), Magnesium Oxide (24), Ferric Citrate, U.S.P. (6.06), Zinc Carbonate (1.65), Manganous Carbonate (0.63), Cupric Carbonate (0.3), Potassium lodate (0.01), Sodium Selenate (0.01025), Ammonium Paramolybdate .4H20 (0.00795), Sodium Metasilicate $.9 \mathrm{H} 20$ (1.45), Chromium Potassium Sulfate .12H20 (0.275), Lithium Chloride (0.0174), Boric Acid (0.0815), Sodium Fluoride (0.0635), Nickel Carbonate (0.0318), Ammonium Vanadate (0.0066), Sucrose, finely powdered (221.026). ${ }^{2}$ AIN-93G Vitamin Mix supplied by Dyets Inc. (Bethlehem, PA), containing ( $/ \mathrm{kg}$ ): Niacin (3), Calcium Pantothenate (1.6), Pyridoxine $\mathrm{HCl}$ (0.7), Thiamine $\mathrm{HCl}$ (0.6), Riboflavin (0.6), Folic Acid (0.2), Biotin (0.02), Vitamin E Acetate (500 IU/g) (15), Vitamin B12 (0.1\%) (2.5), Vitamin A Palmitate (500 000 IU/g) (0.8), Vitamin D3 (400 $000 \mathrm{lU} / \mathrm{g}$ ) (0.25), Vitamin K1/Dextrose Mix (10 mg/g) (7.5), Sucrose (967.23). ${ }^{3}$ Cherry powder contributed with $5.1 \mathrm{~g}$ fiber $/ \mathrm{kg}$ diet and $759 \mathrm{mg}$ GAE/100 g of total phenolics ( $629 \mathrm{mg} \mathrm{GAE} / 100 \mathrm{~g}$ extractable and $130 \mathrm{mg} \mathrm{GAE} / 100 \mathrm{~g}$ non-extractable or bound phenolics). Cherry powder was processed by Powder Pure (The Dalles, OR) and contains $80 \%$ dark sweet cherry puree (Bing variety), $20 \%$ organic rice maltodextrin and $2 \%$ silicon dioxide. 
1 Table 1 Diets utilized in this study without cherry supplementation (control) and with 10\%

2 cherry supplementation.

\begin{tabular}{|c|c|c|c|c|}
\hline \multirow[b]{2}{*}{ Ingredient } & \multicolumn{2}{|l|}{ Control } & \multicolumn{2}{|c|}{ Cherry $10 \%$} \\
\hline & Weight (g) & Kcal & Weight $(g)$ & Kcal \\
\hline Casein & 100 & 400 & 100 & 400 \\
\hline Maltodextrin & 66 & 264 & 66 & 264 \\
\hline Sucrose & 50 & 200 & 50 & 200 \\
\hline Cellulose & 25 & 0 & 25 & 0 \\
\hline Mineral Mix ${ }^{1}$ & 17.5 & 0 & 17.5 & 0 \\
\hline Vitamin $\mathrm{Mix}^{2}$ & 5 & 0 & 5 & 0 \\
\hline L-Cysteine & 1.5 & 6 & 1.5 & 6 \\
\hline Choline Bitartrate & 1.25 & 0 & 1.25 & 0 \\
\hline $\begin{array}{l}\text { t- } \\
\text { Butylhydroquinone }\end{array}$ & 0.007 & 0 & 0.007 & 0 \\
\hline Cornstarch & 198.75 & 795 & 98.75 & 395 \\
\hline Soybean Oil & 35 & 315 & 35 & 315 \\
\hline Cherry powder ${ }^{3}$ & 0 & 0 & 100 & 400 \\
\hline Agar & 20 & 0 & 20 & 0 \\
\hline Water & 480 & 0 & 480 & 0 \\
\hline Total & 1,000 & 1,980 & 1,000 & 1,980 \\
\hline
\end{tabular}

$4 \quad{ }^{1}$ AIN-93G-MX supplied by Dyets Inc. (Bethlehem, PA), containing (g/kg): Calcium Carbonate 5 (357), Potassium Phosphate, monobasic (196), Potassium Citrate .H20 (70.78), Sodium Chloride 6 (74), Potassium Sulfate (46.6), Magnesium Oxide (24), Ferric Citrate, U.S.P. (6.06), Zinc

7 Carbonate (1.65), Manganous Carbonate (0.63), Cupric Carbonate (0.3), Potassium Iodate (0.01),

8 Sodium Selenate (0.01025), Ammonium Paramolybdate .4H20 (0.00795), Sodium Metasilicate

9 .9H20 (1.45), Chromium Potassium Sulfate .12H20 (0.275), Lithium Chloride (0.0174), Boric 10 Acid (0.0815), Sodium Fluoride (0.0635), Nickel Carbonate (0.0318), Ammonium Vanadate 11 (0.0066), Sucrose, finely powdered (221.026). ${ }^{2}$ AIN-93G Vitamin Mix supplied by Dyets Inc. 12 (Bethlehem, PA), containing (g/kg): Niacin (3), Calcium Pantothenate (1.6), Pyridoxine $\mathrm{HCl}$ 13 (0.7), Thiamine $\mathrm{HCl}$ (0.6), Riboflavin (0.6), Folic Acid (0.2), Biotin (0.02), Vitamin E Acetate 14 (500 IU/g) (15), Vitamin B12 (0.1\%) (2.5), Vitamin A Palmitate (500 $000 \mathrm{IU} / \mathrm{g})(0.8)$, Vitamin 15 D3 (400 000 IU/g) (0.25), Vitamin K1/Dextrose Mix (10 mg/g) (7.5), Sucrose (967.23). 
$16{ }^{3}$ Cherry powder contributed with $5.1 \mathrm{~g}$ fiber $/ \mathrm{kg}$ diet and $759 \mathrm{mg} \mathrm{GAE} / 100 \mathrm{~g}$ of total phenolics 17 (629 mg GAE/100g extractable and $130 \mathrm{mg} \mathrm{GAE} / 100 \mathrm{~g}$ non-extractable or bound phenolics). 18 Cherry powder was processed by Powder Pure (The Dalles, OR) and contains $80 \%$ dark sweet 19 cherry puree (Bing variety), 20\% organic rice maltodextrin and $2 \%$ silicon dioxide. 


\section{Table 2 (on next page)}

PICRUSt results (average percentages) for the statistically significant features ( $p<0.05$ adjusted $p$-values*).

$\downarrow$ lowest, $\uparrow$ highest. *We removed 5 features related to human diseases that also reached statistical significance because of their questionable relevance to this study. 
1 Table 2 PICRUSt results (average percentages) for the statistically significant features ( $<<0.05$

2 adjusted p-values*).

\begin{tabular}{|c|c|c|c|c|c|c|}
\hline Level 1 & Level 2 & Level 3 & $\begin{array}{l}\text { Obese } \\
\text { controls }\end{array}$ & $\begin{array}{c}\text { Obese } \\
\text { supplemented }\end{array}$ & $\begin{array}{l}\text { Lean } \\
\text { controls }\end{array}$ & $\begin{array}{l}\text { Adjusted } p \\
\text { values }\end{array}$ \\
\hline Metabolism & $\begin{array}{l}\text { Amino Acid } \\
\text { Metabolism }\end{array}$ & $\begin{array}{l}\text { Amino acid related } \\
\text { enzymes }\end{array}$ & $1.56 \downarrow$ & 1.64 & $1.74 \uparrow$ & 0.008 \\
\hline Metabolism & $\begin{array}{l}\text { Amino Acid } \\
\text { Metabolism }\end{array}$ & Histidine metabolism & $0.61 \downarrow$ & 0.72 & $0.79 \uparrow$ & 0.011 \\
\hline Metabolism & $\begin{array}{l}\text { Biosynthesis of Other } \\
\text { Secondary } \\
\text { Metabolites }\end{array}$ & $\begin{array}{l}\text { Stilbenoid, } \\
\text { diarylheptanoid and } \\
\text { gingerol biosynthesis }\end{array}$ & $0.00 \downarrow$ & 0.00 & $0.01 \uparrow$ & 0.020 \\
\hline Metabolism & $\begin{array}{l}\text { Carbohydrate } \\
\text { Metabolism }\end{array}$ & $\begin{array}{l}\text { Ascorbate and aldarate } \\
\text { metabolism }\end{array}$ & $0.21 \uparrow$ & 0.19 & $0.13 \downarrow$ & 0.023 \\
\hline Metabolism & $\begin{array}{l}\text { Carbohydrate } \\
\text { Metabolism }\end{array}$ & Butanoate metabolism & $0.85 \uparrow$ & 0.74 & $0.73 \downarrow$ & 0.038 \\
\hline Metabolism & $\begin{array}{l}\text { Carbohydrate } \\
\text { Metabolism }\end{array}$ & $\begin{array}{l}\text { Pentose and glucuronate } \\
\text { interconversions }\end{array}$ & 0.70 & $0.73 \uparrow$ & $0.62 \downarrow$ & 0.049 \\
\hline Metabolism & $\begin{array}{l}\text { Carbohydrate } \\
\text { Metabolism }\end{array}$ & $\begin{array}{l}\text { Pentose phosphate } \\
\text { pathway }\end{array}$ & $0.98 \downarrow$ & $1.09 \uparrow$ & 1.01 & 0.033 \\
\hline Metabolism & Energy Metabolism & $\begin{array}{l}\text { Carbon fixation in } \\
\text { photosynthetic organisms }\end{array}$ & $0.68 \downarrow$ & $0.74 \uparrow$ & 0.73 & 0.013 \\
\hline Metabolism & Enzyme Families & Peptidases & $2.08 \downarrow$ & 2.14 & $2.32 \uparrow$ & 0.026 \\
\hline Metabolism & Enzyme Families & Protein kinases & $0.49 \uparrow$ & 0.40 & $0.34 \downarrow$ & 0.004 \\
\hline Metabolism & $\begin{array}{l}\text { Glycan Biosynthesis } \\
\text { and Metabolism }\end{array}$ & $\begin{array}{l}\text { Peptidoglycan } \\
\text { biosynthesis }\end{array}$ & $0.83 \downarrow$ & 0.84 & $0.94 \uparrow$ & 0.039 \\
\hline Metabolism & Lipid Metabolism & $\begin{array}{l}\text { alpha-Linolenic acid } \\
\text { metabolism }\end{array}$ & $0.03 \uparrow$ & 0.01 & $0.01 \downarrow$ & 0.025 \\
\hline Metabolism & $\begin{array}{l}\text { Metabolism of } \\
\text { Cofactors and } \\
\text { Vitamins }\end{array}$ & One carbon pool by folate & $0.64 \downarrow$ & 0.72 & $0.76 \uparrow$ & 0.036 \\
\hline Metabolism & $\begin{array}{l}\text { Metabolism of } \\
\text { Cofactors and } \\
\text { Vitamins }\end{array}$ & Thiamine metabolism & $0.51 \downarrow$ & 0.56 & $0.58 \uparrow$ & 0.035 \\
\hline Metabolism & $\begin{array}{l}\text { Metabolism of } \\
\text { Terpenoids and } \\
\text { Polyketides }\end{array}$ & $\begin{array}{l}\text { Terpenoid backbone } \\
\text { biosynthesis }\end{array}$ & $0.54 \downarrow$ & 0.61 & $0.69 \uparrow$ & 0.003 \\
\hline Metabolism & $\begin{array}{l}\text { Xenobiotics } \\
\text { Biodegradation and } \\
\text { Metabolism } \\
\end{array}$ & $\begin{array}{l}\text { 1,1,1-Trichloro-2,2-bis(4- } \\
\text { chlorophenyl)ethane } \\
\text { (DDT) degradation }\end{array}$ & $0.00 \downarrow$ & $0.00 \uparrow$ & 0.00 & 0.015 \\
\hline $\begin{array}{l}\text { Genetic } \\
\text { Information } \\
\text { Processing }\end{array}$ & $\begin{array}{l}\text { Replication and } \\
\text { Repair }\end{array}$ & Mismatch repair & $0.84 \downarrow$ & 0.92 & $0.97 \uparrow$ & 0.005 \\
\hline $\begin{array}{l}\text { Genetic } \\
\text { Information } \\
\text { Processing }\end{array}$ & Translation & Ribosome & $2.26 \downarrow$ & 2.46 & $2.82 \uparrow$ & 0.006 \\
\hline $\begin{array}{l}\text { Genetic } \\
\text { Information } \\
\text { Processing }\end{array}$ & $\begin{array}{l}\text { Replication and } \\
\text { Repair }\end{array}$ & DNA replication proteins & $1.28 \downarrow$ & 1.38 & $1.49 \uparrow$ & 0.006 \\
\hline $\begin{array}{l}\text { Genetic } \\
\text { Information }\end{array}$ & Translation & Translation factors & $0.54 \downarrow$ & 0.59 & $0.66 \uparrow$ & 0.006 \\
\hline
\end{tabular}




\begin{tabular}{|l|l|l|c|c|c|c|}
\hline Processing & & & & & & \\
\hline $\begin{array}{l}\text { Genetic } \\
\text { Information } \\
\text { Processing }\end{array}$ & $\begin{array}{l}\text { Replication and } \\
\text { Repair }\end{array}$ & Base excision repair & $0.47 \downarrow$ & 0.51 & $0.55 \uparrow$ & 0.011 \\
\hline $\begin{array}{l}\text { Genetic } \\
\text { Information } \\
\text { Processing }\end{array}$ & $\begin{array}{l}\text { Replication and } \\
\text { Repair }\end{array}$ & $\begin{array}{l}\text { DNA repair and } \\
\text { recombination proteins }\end{array}$ & $2.99 \downarrow$ & 3.15 & $3.37 \uparrow$ & 0.012 \\
\hline $\begin{array}{l}\text { Genetic } \\
\text { Information } \\
\text { Processing }\end{array}$ & $\begin{array}{l}\text { Replication and } \\
\text { Repair }\end{array}$ & Nucleotide excision repair & $0.37 \downarrow$ & 0.45 & $0.46 \uparrow$ & 0.014 \\
\hline $\begin{array}{l}\text { Genetic } \\
\text { Information } \\
\text { Processing }\end{array}$ & $\begin{array}{l}\text { Replication and } \\
\text { Repair }\end{array}$ & DNA replication & $0.69 \downarrow$ & 0.74 & $0.82 \uparrow$ & 0.016 \\
\hline $\begin{array}{l}\text { Genetic } \\
\text { Information } \\
\text { Processing }\end{array}$ & Translation & $\begin{array}{l}\text { Aminoacyl-tRNA } \\
\text { biosynthesis }\end{array}$ & $1.16 \downarrow$ & 1.25 & $1.39 \uparrow$ & 0.016 \\
\hline $\begin{array}{l}\text { Genetic } \\
\text { Information } \\
\text { Processing }\end{array}$ & Folding, Sorting and & Protein export & $0.61 \downarrow$ & 0.65 & $0.72 \uparrow$ & 0.017 \\
\hline $\begin{array}{l}\text { Genetic } \\
\text { Information } \\
\text { Processing }\end{array}$ & Transcription & RNA polymerase & $0.16 \downarrow$ & 0.17 & $0.20 \uparrow$ & 0.019 \\
\hline $\begin{array}{l}\text { Genetic } \\
\text { Information } \\
\text { Processing }\end{array}$ & $\begin{array}{l}\text { Replication and } \\
\text { Repair }\end{array}$ & $\begin{array}{l}\text { Homologous } \\
\text { recombination }\end{array}$ & $0.95 \downarrow$ & 0.99 & $1.10 \uparrow$ & 0.022 \\
\hline $\begin{array}{l}\text { Information } \\
\text { Processing }\end{array}$ & Signal Transduction \\
\hline $\begin{array}{l}\text { Environmental } \\
\text { Information } \\
\text { Processing }\end{array}$ & $\begin{array}{l}\text { Two-component system } \\
\text { and Interaction }\end{array}$ & $2.30 \uparrow$ & 1.91 & $1.63 \downarrow$ & 0.024 \\
\hline
\end{tabular}

4

$5 \downarrow$ lowest, $\uparrow$ highest. *We removed 5 features related to human diseases that also reached

6 statistical significance because of their questionable relevance to this study. 


\section{Table 3 (on next page)}

Median (minimum-maximum) SCFA concentrations ( $\mu \mathrm{mol} / \mathrm{mg}$ caecal contents).

$P$ values come from either the Kruskal-Wallis test or the Mann Whitney test when comparing only two treatment groups due to lack of detectable values in one group. Different letters state statistical significance difference. The symbol (-) is included to denote treatment groups where all or most samples were undetectable. The number of samples ( $n$ ) in which the specific SCFA was detected for each experimental group is also included. For most SCFAs, we chose not to perform a statistical comparison because of very low sample size in at least one treatment group (NA or not applicable). Please note that most samples (especially from lean and obese controls) showed undetectable levels of several SCFAs. In our experience this was not due to errors in our analytical methodology, and this is supported by the fact that all samples were treated equally yet most samples from supplemented mice did show detectable levels of most SCFAs. 
1 Table 3 Median (minimum-maximum) SCFA concentrations ( $\mu \mathrm{mol} / \mathrm{mg}$ caecal contents).

2

\begin{tabular}{|l|c|c|c|c|}
\hline & Obese controls & Obese supplemented & Lean controls & $P$ value \\
\hline Caproate & $\begin{array}{c}1.2(0.4-3.9)^{\mathrm{a}} \\
(\mathrm{n}=9)\end{array}$ & $\begin{array}{c}285(217-437)^{\mathrm{b}} \\
(\mathrm{n}=12)\end{array}$ & $\begin{array}{c}1.0(0.4-652)^{\mathrm{a}} \\
(\mathrm{n}=10)\end{array}$ & 0.0033 \\
\hline Methyl butyrate & - & $116(17-405)$ & $62(43-92)$ & NA \\
& $(\mathrm{n}=12)$ & $(\mathrm{n}=3)$ & \\
\hline Butyrate & $6.2(5.3-20)^{\mathrm{a}}$ & - & $11.9(6.1-16.2)^{\mathrm{a}}$ & 0.3511 \\
& $(\mathrm{n}=9)$ & $(\mathrm{n}=7)$ & \\
\hline Propionate & - & $384(258-649)$ & $356(281-438)$ & NA \\
& $(\mathrm{n}=12)$ & $(\mathrm{n}=4)$ & \\
\hline Acetate & $1.9(1.4-1.9)$ & $269.4(128-672)$ & $273.2(40-351)$ & NA \\
& $(\mathrm{n}=3)$ & $(\mathrm{n}=12)$ & $(\mathrm{n}=3)$ & \\
\hline Valerate & - & $15.4(4-48)$ & - & NA \\
& & $(\mathrm{n}=10)$ & & \\
\hline
\end{tabular}

3

$4 \quad P$ values come from either the Kruskal-Wallis test or the Mann Whitney test when comparing

5 only two treatment groups due to lack of detectable values in one group. Different letters state

6 statistical significance difference. The symbol (-) is included to denote treatment groups where

7 all or most samples were undetectable. The number of samples (n) in which the specific SCFA

8 was detected for each experimental group is also included. For most SCFAs, we chose not to

9 perform a statistical comparison because of very low sample size in at least one treatment group

10 (NA or not applicable). Please note that most samples (especially from lean and obese controls)

11 showed undetectable levels of several SCFAs. In our experience this was not due to errors in our

12 analytical methodology, and this is supported by the fact that all samples were treated equally yet

13 most samples from supplemented mice did show detectable levels of most SCFAs. 